Supplier Selection Using Chance-Constrained Data Envelopment Analysis with Nondiscretionary Factors and Stochastic Data

\author{
Majid Azadi \\ Faculty of Economic and Management \\ Islamic Azad University - Sciences and Researches Branch \\ Tehran, Iran \\ E-mail: majid.azadi.edu@ gmail.com \\ Reza Farzipoor Saen \\ Department of International Business and Asian Studies \\ Griffith University - Gold Coast Campus \\ Gold Coast, Queensland 4222, Australia \\ E-mail: farzipour@yahoo.com \\ Madjid Tavana* \\ Professor, Management Information Systems \\ Lindback Distinguished Chair of Information Systems \\ La Salle University \\ Philadelphia, PA 19141, U.S.A. \\ Phone: (215) 951-1129 \\ Fax: (267) 295-2854 \\ E-mail: tavana@lasalle.edu \\ URL: $\underline{\text { http://lasalle.edu/ tavana }}$
}

*Corresponding Author

ACKNOWLEDGEMENT

The authors would like to thank the anonymous reviewers and the editor for their insightful comments and suggestions. 


\section{Biographical Notes}

Majid Azadi is a strategic and operational management consultant. He is currently pursuing his graduate education in Industrial Management at the Islamic Azad University - Sciences and Researches Branch in Iran. His research interests include Productivity Analysis, Artificial Neural Networks, Integer Programming, Game Theory, Non-Linear Programming, Supply chain management, Third-Party Reverse Logistics, Genetic algorithm, and Goal programming.

Reza Farzipoor Saen is an Associate Professor in the Department of International Business and Asian Studies at the Griffith University in Australia. He obtained his $\mathrm{PhD}$ in Industrial Management from the Islamic Azad University - Science and Research Branch in Iran. He has published over 45 refereed papers in many prestigious journals such as Annals of Operations Research, Journal of the Operational Research Society, European Journal of Operational Research, Applied Mathematics and Computation, Applied Mathematical Modelling, World Applied Sciences Journal, International Journal of Advanced Manufacturing Technology, International Journal of Applied Management and Technology, and Asia Pacific Management Review, among others.

Madjid Tavana is a Professor of Management Information Systems and Decision Sciences and the Lindback Distinguished Chair of Information Systems at La Salle University where he served as Chairman of the Management Department and Director of the Center for Technology and Management. He has been a distinguished research fellow at NASA's Kennedy Space Center, NASA's Johnson Space Center, Naval Research Laboratory - Stennis Space Center, and Air Force Research Laboratory. He was awarded the prestigious Space Act Award by NASA in 2005. He holds an MBA, a PMIS, and a PhD in Management Information Systems. Dr. Tavana received his post-doctoral diploma in strategic information systems from the Wharton School of the University of Pennsylvania. He is the Editor-inChief for the International Journal of Strategic Decision Sciences, the International Journal of Enterprise Information Systems, and the International Journal of Applied Decision Sciences. He has published in journals such as Decision Sciences, Interfaces, Information Systems, Annals of Operations Research, Information and Management, Journal of the Operational Research Society, Computers and Operations Research, and Advances in Engineering Software, among others. 


\title{
Supplier Selection Using Chance-Constrained Data Envelopment Analysis with Nondiscretionary Factors and Stochastic Data
}

\begin{abstract}
The changing economic conditions have challenged many organizations to search for more efficient and effective ways to manage their supply chain. During recent years supplier selection decisions have received considerable attention in the supply chain management (SCM) literature. There are four major decisions that are related to the supplier selection process: what product or services to order, from which suppliers, in what quantities, and in which time periods? Data envelopment analysis (DEA) has been successfully used to select the most efficient supplier(s) in a supply chain. In this study, we introduce a novel supplier selection model using chance-constrained DEA with Nondiscretionary Factors and Stochastic Data. We propose a deterministic equivalent of the stochastic nondiscretionary model and convert this deterministic problem into a quadratic programming problem. This quadratic programming problem is then solved using algorithms available for this class of problems. We perform sensitivity analysis on the proposed nondiscretionary model and present a case study to demonstrate the applicability of the proposed approach and to exhibit the efficacy of the procedures and algorithms.
\end{abstract}

Keywords: Supplier Selection; Supply Chain Management; Data Envelopment Analysis; Chance Constrained Programming; Nondiscretionary Factors; Stochastic Data; Quadratic Programming. 


\section{Introduction}

Supply chain management (SCM) encompasses the entire value chain and addresses materials and supply management from the extraction of raw materials to its end of useful life (Tan, 2001). One of the most important activities in SCM is the purchasing function (Cakravastia and Takahashi, 2004; Chou and Chang, 2008). Purchasing plays a key role in corporate strategy through the selection of suppliers that support the organization's competitive position. Selecting the most efficient suppliers considerably reduces the purchasing expenditure and enhances corporate competitiveness, which is why numerous experts believe that supplier evaluation and selection is one of the most significant activities in a purchasing department (Haq and Kannan, 2006). Supplier selection is the procedure by which suppliers are reviewed, evaluated, and selected to become associated with the company's supply chain.

Shin et al. (2000) argue that several significant factors have caused the recent shift to single sourcing or a reduced supplier center. First, multiple sourcing prevents suppliers from attaining the economies of scale based on order volume and learning curve effect. Second, multiple supplier system can be more costly than a decreased supplier base. For example, running a large number of suppliers for a particular item increases labor and ordering costs associated with managing multiple resource inventories. In the meantime, multiple sourcing may lower the overall quality because of the increased variation in incoming quality among the suppliers. Third, a reduced supplier base can eliminate distrust among the purchasers and suppliers due to the lack of communication. Fourth, global rivalry forces companies to find the best suppliers in the world.

Several mathematical programming techniques have been proposed for supplier selection in the literature. Table 1 categorizes the papers reviewed in this study with respect to these techniques. Nevertheless, because of the intricacy of the decision making process involved in supplier selection, all the aforementioned references in Table 1, except for the DEA model; rely heavily on some sort of procedure for determining the importance weights associated with the performance criteria. These importance weights are generally subjective and it is often difficult for the decision makers to precisely assign numbers to their preferences. This is especially intimidating for the decision makers when the number of performance criteria is increased. Furthermore, these methods do not consider stochastic data in the supplier selection process.

\section{Insert Table 1 Here}

Discretionary models of DEA assume that all inputs and outputs are discretionary, 
i.e., controlled by the management of each decision making unit (DMU) and varied at his/her discretion. Thus, failure of a DMU to produce the maximal output level with the minimal input consumption results in a decreased efficiency score. In any realistic situation, however, there may exist exogenously fixed or nondiscretionary inputs or outputs that are beyond the control of a DMU's management. Ray (1988) argues that technical inefficiency is simply the result of a failure to incorporate all relevant nondiscretionary variables. Instances from the DEA literature include snowfall or weather in evaluating the efficiency of maintenance units, soil characteristics and topography in different farms, number of competitors in the branches of a restaurant chain, age of facilities in different universities, and number of transactions (for a purely gratis service) in library performance (Farzipoor Saen, 2005).

Chance constrained programming developed by Charnes and Cooper (1963) is an operations research approach for optimization under uncertainty when some or all coefficients in a linear program are random variables distributed in accordance with some probability law. In chance constrained programming, the optimization problem is concerned with identification of the value of the decision variables so that the expected loss in the criterion is minimized subject to the requirement that the probability that any given constraint is violated is not allowed to exceed some a priori specified level (Olesen, 2006). The stochastic input and output variations in DEA have been studied by Sengupta (1982, 1987, 1990, 1997, 1998, 2000), Land et al. (1993), Olesen and Petersen (1995), and Li (1998). Morita and Seiford (1999), Sueyoshi (2000), Huang and Li (2001), Cooper et al. (2004), and Olesen (2006). Talluri et al. (2006) utilized the CCP model proposed by Land et al. (1993) for supplier selection but did not consider nondiscretionary factors.

We use the CCP model proposed by Cooper et al. (2004) since it not only has the advantages proposed by Land et al. (1993), but also it opens up possible new routes for "sensitivity analysis". Additionally, it can be solved by a deterministic equivalent.

To the best of our knowledge, there are no references that deal with supplier selection in the presence of both nondiscretionary factors and stochastic data. The objective of this paper is to propose a method that allows for supplier evaluation in the presence of both stochastic and nondiscretionary factors. In summary, the approach proposed in this study has the following distinctive features:

- The stochastic data and nondiscretionary factors are considered simultaneously in the model.

- A stochastic model is developed and its deterministic equivalent which is a nonlinear 
program is derived.

- It is shown that the deterministic equivalent of the stochastic nondiscretionary factors model can be converted into a quadratic program.

- Sensitivity analysis of the proposed model is discussed with respect to changes in the parameters.

- The proposed model does not require the decision maker(s) to provide importance weights associated with the decision criteria.

- The proposed model is uniquely applied to a supplier selection problem.

This paper is organized into five sections. Section 2 presents the mathematical notations used in our model. In Section 3 we then present the details of the proposed method followed by a case study to demonstrate the applicability of the method and to exhibit the efficacy of the procedures and algorithms in Section 4. We close the paper with conclusions and future research directions in Section 5.

\section{Mathematical notations}

$j=1, \ldots, n \quad$ The collection of suppliers (DMUs)

$r=1, \ldots, s \quad$ The set of outputs

$i=1, \ldots, m \quad$ The set of inputs

$D M U_{o} \quad$ The DMU under investigation

$y_{r j} \quad$ The mean of the $r$ th output of the $j$ th DMU

$x_{i j} \quad$ The mean of the $i$ th input of the $j$ th DMU

$y_{\text {ro }} \quad$ The mean of the $r$ th output of the $\mathrm{DMU}_{o}$

$x_{i o} \quad$ The mean of the $i$ th input of the $\mathrm{DMU}_{o}$

$\check{y}_{r j} \quad$ The $r$ th output of the $j$ th DMU

$\check{x}_{i j} \quad$ The $i$ th input of the $j$ th DMU

$\check{y}_{r o} \quad$ The $r$ th output of the $\mathrm{DMU}_{o}$

$\check{x}_{i o} \quad$ The $i$ th input of the $\mathrm{DMU}_{o}$

$\sim \quad$ Used to identify the inputs and outputs as random variables with a known joint probability distribution

$\eta \quad$ The best possible relative efficiency achieved by $\mathrm{DMU}_{o}$

$\Phi^{-1} \quad$ The inverse of the standard normal distribution function

$t_{r}^{+} \quad$ The shortfalls of the $r$ th output

$t_{i}^{-} \quad$ The excesses of the $i$ th input

$\varepsilon \quad$ The non-Archimedean positive infinitesimal 


$\begin{array}{ll}\sigma_{r}^{o} & \text { The standard deviation of the } r \text { th output } \\ \sigma_{i}^{I} & \text { The standard deviation of the } i \text { th input } \\ \alpha & \text { The risk that is between zero and } 1 \\ \text { Vary } y_{r o} & \text { The } r \text { th output variance of the } \mathrm{DMU}_{o} \\ \text { Var } x_{i o} & \text { The } i \text { th input variance of the DMU } \\ \xi, \varsigma, \text { and } \zeta & \text { The external slacks } \\ Z & \text { The standard normal random variable } \\ \mu & {\left[\mu_{j}\right] \text { vector of DMU loadings, determining the best practice for the } \mathrm{DMU}_{o}} \\ E & \text { The expected value }\end{array}$

\section{Proposed method}

Data envelopment analysis (DEA) is a widely used mathematical programming technique for comparing the inputs and outputs of a set of homogenous decision making units (DMUs) by evaluating their relative efficiency. The field of DEA has grown at an exponential rate since the pioneering papers of Farrell (1957) and Charnes et al. (1978). DEA is generally used to measure the relative efficiencies of a set of DMUs producing multiple outputs from multiple inputs.

In recent years, DEA has been used to measure the efficiency of DMUs in many different settings such as efficiency and effectiveness in operating management (Parkan, 2006), supply chain management (Wong et al., 2008), the farming industry (Mulwa et al., 2009), the banking industry (Azadeh et al., 2010a, 2010b; Cooper et al., 2008), the investment banking industry (Emrouznejad and Thanassoulis, 2010; Ho, 2007), the health care industry (Dharmapala, 2009), and the hotel industry (Cheng et al., 2010).

Suppose that the output variables are partitioned into subsets of discretionary $(D)$ and nondiscretionary $(N)$ variables,

$O=\{1,2, \ldots, s\}=O_{D} \cup O_{N}, \quad O_{D} \cap O_{N}=\Phi$.

The formulation for the output-oriented nondiscretionary model with nondiscretionary variables is given by Banker and Morey (1986).

$\begin{array}{ll}\text { Max } & \eta+\varepsilon\left(\sum_{i=1}^{m} t_{i}^{-}+\sum_{r \in D} t_{r}^{+}\right) \\ \text {s.t. } \quad \check{x}_{i o}=\sum_{j=1}^{n} \check{x}_{i j} \mu_{j}+t_{i}^{-}, \quad i=1, \ldots, m ;\end{array}$ 


$$
\begin{array}{ll}
\eta \check{y}_{r o}=\sum_{j=1}^{n} \check{y}_{r j} \mu_{j}-t_{r}^{+}, & r \in D ; \\
\check{y}_{r o}=\sum_{j=1}^{n} \check{y}_{r j} \mu_{j}-t_{r}^{+}, & r \in N ; \\
t_{r}^{+}=0, & r \in N ; \\
\mu_{j} \geq 0, & j=1, \ldots, n ; \\
t_{i}^{-} \geq 0, & i=1, \ldots, m ; \\
t_{r}^{+} \geq 0, & r=1, \ldots, s .
\end{array}
$$

Definition 1. (Stochastic efficiency) $\mathrm{DMU}_{o}$ is DEA stochastic efficient if and only if the following two conditions are both satisfied:

(i) $\eta^{*}=1$

(ii) $t_{i}^{-*}=t_{r}^{+*}=0, \quad \forall i, r$.

Notice that '*' refers to optimal value. Charnes et al. (1991) have shown that the performance of the DMUs can be separated into the following four classes: E, E', F, and N; where $\mathrm{E}$ is a set of efficient DMUs which are also maximum points and $\mathrm{E}^{\prime}$ is a set of efficient DMUs which are not maximum points. Both E and E' satisfy Definition 1. F is a set of points on the frontier which are not efficient because they satisfy (i) but not (ii) in Definition 1 . Lastly, $\mathrm{N}$ consists of all points which are not on a frontier and are therefore inefficient.

The stochastic nondiscretionary models are developed to accommodate the possible existence of stochastic variability in the data. As we know, the typical DEA models cannot accommodate stochastic variations in the input and output data, hence, DEA efficiency measurement may be sensitive to such variations. For instance, a DMU which is measured as efficient relative to the other DMUs, might turn inefficient if such random variations are considered. In what follows, a stochastic version of the output oriented nondiscretionary model (1) is presented to allow for the possibility of stochastic alterations in the input and output data.

We suppose that all the inputs and outputs are random variables with multivariate normal distributions and known parameters.

$\operatorname{Max} \quad \eta$

s.t. $p\left\{\sum_{j=1}^{n} \tilde{x}_{i j} \mu_{j} \leq \tilde{x}_{i o}\right\} \geq 1-\alpha, \quad i=1, \ldots, m$; 


$$
\begin{array}{ll}
p\left\{\sum_{j=1}^{n} \tilde{y}_{r j} \mu_{j} \geq \eta \tilde{y}_{r o}\right\} \geq 1-\alpha, & r \in D ; \\
p\left\{\sum_{j=1}^{n} \tilde{y}_{r j} \mu_{j} \geq \tilde{y}_{r o}\right\} \geq 1-\alpha, & r \in N ; \\
\sum_{j=1}^{n} \mu_{j}=1 ; & \\
\mu_{j} \geq 0, & j=1, \ldots, n .
\end{array}
$$

Definition 2. (DEA efficiency) $\mathrm{DMU}_{o}$ is DEA efficient if and only if the following two conditions are both satisfied;

$(\square) \eta^{*}=1$

(ii) The slack values are zero for the entire optimal solutions.

The second condition refers to all alternate optima for the reason that the second stage optimization associated with $\varepsilon>0$ is not utilized in Model (2). As $j=0$ is one of the $n$ $\mathrm{DMU}_{j}$, we can always get a solution with $\eta=1, \mu_{o}=1$ and $\mu_{j}=0(j \neq 0)$ and all slacks zero. Nevertheless, this solution does not require to be maximal. It follows that a maximum with $\eta^{*}>1$ in Model (2) for any sample of $j=1, \ldots, n$ observations means that the $\mathrm{DMU}_{o}$ under evaluation is not efficient, this is because when the probability level is specified via $\alpha$, all outputs of $\mathrm{DMU}_{o}$ can be increased to $\eta^{*} \tilde{y}_{r o}>\tilde{y}_{r o}, r \in D$, via using a convex combination of other DMUs which also satisfy

$$
p\left\{\sum_{j=1}^{n} \tilde{x}_{i j} \mu_{j} \leq \tilde{x}_{i o}\right\} \geq 1-\alpha, \quad i=1, \ldots, m
$$

Now assume $\zeta_{r}>0$ is the "external slack" for the rth output. The external slacks are those slacks that are outside the brackets. We can select the value of this external slack, which is not stochastic, so it satisfies

$$
p\left\{\sum_{j=1}^{n} \tilde{y}_{r j} \mu_{j}-\eta \tilde{y}_{r o} \geq 0\right\}=(1-\alpha)+\varsigma_{r}
$$

Then these must exist a positive number $t_{r}^{+}>0$ such that

$$
p\left\{\sum_{j=1}^{n} \tilde{y}_{r j} \mu_{j}-\eta \tilde{y}_{r o} \geq t_{r}^{+}\right\}=1-\alpha
$$

This positive value of $t_{r}^{+}$permits a further increase in $\tilde{y}_{r o}$ for any set of sample 
observations devoid of diminishing any other input or output. It is easy to demonstrate that $\varsigma_{r}=0$ if and only if $t_{r}^{+}=0$.

Also, we have

$p\left\{\sum_{j=1}^{n} \tilde{y}_{r j} \mu_{j}-\tilde{y}_{r o} \geq 0\right\}=(1-\alpha)+\zeta_{r}$

Consequently,

$p\left\{\sum_{j=1}^{n} \tilde{y}_{r j} \mu_{j}-\tilde{y}_{r o} \geq t_{r}^{+}\right\}=1-\alpha$

In an analogous manner, presume $\xi_{i}>0$ represents the external slack for the $i$ th input chance-constraint. Let its value satisfy

$p\left\{\sum_{j=1}^{n} \tilde{x}_{i j} \mu_{j}-\tilde{x}_{i o} \leq 0\right\}=(1-\alpha)+\xi_{i}$

Then there must exist a positive number $t_{i}^{-}>0$ such that

$p\left\{\sum_{j=1}^{n} \tilde{x}_{i j} \mu_{j}+t_{i}^{-} \leq \tilde{x}_{i o}\right\}=1-\alpha$

Such a positive value of $t_{i}^{-}$permits a decrease in $\tilde{x}_{i o}$ for any sample without diminishing any other input or output with respect to the indicated probabilities. It is easy to demonstrate that $\xi=0$ if and only if $t_{i}^{-}=0$.

Consider the non-Archimedean infinitesimal, $\varepsilon>0$, so that stochastic efficiencies and inefficiencies can be characterized via the following model, Relations (3)-(9), can replace Relation (3),

$\operatorname{Max} \eta+\varepsilon\left(\sum_{i=1}^{m} t_{i}^{-}+\sum_{r \in D} t_{r}^{+}\right)$

s.t.

$p\left\{\sum_{j=1}^{n} \widetilde{x}_{i j} \mu_{j}+t_{i}^{-} \leq \widetilde{x}_{i o}\right\}=1-\alpha, \quad i=1, \ldots, m ;$

$p\left\{\sum_{j=1}^{n} \widetilde{y}_{r j} \mu_{j}-\eta \widetilde{y}_{r o} \geq t_{r}^{+}\right\}=1-\alpha, \quad r \in D ;$ 
$p\left\{\sum_{j=1}^{n} \widetilde{y}_{r j} \mu_{j}-\widetilde{y}_{r o} \geq t_{r}^{+}\right\}=1-\alpha, \quad r \in N ;$

$\sum_{j=1}^{n} \mu_{j}=1$

$t_{r}^{+}=0$,

$r \in N$;

$\mu_{j} \geq 0$,

$j=1, \ldots, n$;

$t_{i}^{-} \geq 0$,

$i=1, \ldots$;

$t_{r}^{+} \geq 0$, $r=1, \ldots, s$.

This leads to the following definition.

Definition 3. $\mathrm{DMU}_{o}$ is stochastic efficient if and only if the following two conditions are both satisfied

(i) $\eta^{*}=1$

(ii) $t_{r}^{+*}=t_{i}^{-*}=0 \quad \forall i, r$.

This definition aligns more closely with Definition 1 since $\varepsilon>0$ in the objective function of Model (10) makes it unnecessary to refer to 'all optimal solutions,' as in Definition 2. Although it has the same form as Definition 1, it differs in that probabilistic components are considered. For example, as determined by the selection of $\alpha$, there is a possibility that $\mathrm{DMU}_{o}$ will not be efficient even when the assumptions of Definitions 3 are satisfied.

Following Cooper et al. (1996), we suppose that the inputs and outputs are random variables with a multivariate normal distribution and known parameters. We also limit our concentration to the class of zero-order decision rules. The selection of multivariate normal distributions and zero-order rules are less restrictive than might appear on the surface. Conversions are obtainable for bringing other kinds of distributions into approximately normal form-as was done in Charnes et al. (1958) when they found it necessary to treat extremely skewed distributions with log-normal estimates (see Charnes et al. (1958) and Charnes and Cooper (1961)).

For the 2nd constraint in Model (10), we have

$$
p\left\{\frac{\sum_{j=1}^{n} \tilde{y}_{r j} \mu_{j}-\eta_{o} \tilde{y}_{r o}-E\left(\sum_{j=1}^{n} \tilde{y}_{r j} \mu_{j}-\eta_{o} \tilde{y}_{r o}\right)}{\sqrt{\operatorname{var}\left\{\sum_{j=1}^{n} \tilde{y}_{r j} \mu_{j}-\eta_{o} \tilde{y}_{r o}\right\}}} \leq \frac{t_{r}^{+}-E\left(\sum_{j=1}^{n} \tilde{y}_{r j} \mu_{j}-\eta_{o} \tilde{y}_{r o}\right)}{\sqrt{\operatorname{var}\left\{\sum_{j=1}^{n} \tilde{y}_{r j} \mu_{j}-\eta_{o} \tilde{y}_{r o}\right\}}}\right\}=\alpha
$$

We should note that the conversion process has been discussed for constraint 2 in 
Model (10) and the same process could be repeated for constraints 1 and 3.

For the sake of simplicity we indicate $\sqrt{\operatorname{var}\left\{\sum_{j=1}^{n} \tilde{y}_{r j} \mu_{j}-\eta_{o} \tilde{y}_{r o}\right\}}$ by $\sigma_{r}^{o}\left(\eta_{o}, \mu\right)$. Hence,

$p\left\{\frac{\sum_{j=1}^{n} \tilde{y}_{r j} \mu_{j}-\eta_{o} \tilde{y}_{r o}-\sum_{j=1}^{n} y_{r j} \mu_{j}+\eta_{o} y_{r o}}{\sigma_{r}^{o}\left(\eta_{o}, \mu\right)} \leq \frac{t_{r}^{+}-\sum_{j=1}^{n} y_{r j} \mu_{j}+\eta_{o} y_{r o}}{\sigma_{r}^{o}\left(\eta_{o}, \mu\right)}\right\}=\alpha$

In other words

$p\left\{Z \leq \frac{t_{r}^{+}-\sum_{j=1}^{n} y_{r j} \mu_{j}+\eta_{o} y_{r o}}{\sigma_{r}^{o}\left(\eta_{o}, \mu\right)}\right\}=\alpha$

Where $\mathrm{Z}$ is a normal standard variable, and we have,

$\Phi\left\{\frac{t_{r}^{+}-\sum_{j=1}^{n} y_{r j} \mu_{j}+\eta_{o} y_{r o}}{\sigma_{r}^{o}\left(\eta_{o}, \mu\right)}\right\}=\alpha$

or

$\eta_{o} y_{r o}-\sum_{j=1}^{n} y_{r j} \mu_{j}+t_{r}^{+}-\Phi^{-1}(\alpha) \sigma_{r}^{o}\left(\eta_{o}, \mu\right)=0$,

The deterministic equivalents for Model (10) are,

$\operatorname{Max} \eta+\varepsilon\left(\sum_{i=1}^{m} t_{i}^{-}+\sum_{r \in D} t_{r}^{+}\right)$

st.

$\sum_{j=1}^{n} x_{i j} \mu_{j}+t_{i}^{-}-\Phi^{-1}(\alpha) \sigma_{i}^{I}(\mu)=x_{i o}, \quad i=1, \ldots, m$;

$\eta y_{r o}-\sum_{j=1}^{n} y_{r j} \mu_{j}+t_{r}^{+}-\Phi^{-1}(\alpha) \delta_{r}^{o}(\eta, \mu)=0, \quad r \in D ;$

$\sum_{j=1}^{n} y_{r j} \mu_{j}-t_{r}^{+}-\Phi^{-1}(\alpha) \delta_{r}^{o}(\mu)-y_{r o}=0, \quad r \in N$;

$t_{r}^{+}=0, \quad r \in N$;

$\mu_{j} \geq 0, \quad j=1, \ldots, n$;

$t_{i}^{-} \geq 0, \quad i=1, \ldots, m$;

$t_{r}^{+} \geq 0, \quad r=1, \ldots, s$. 


$$
\begin{aligned}
\sigma_{i}^{I}(\mu)^{2}=\operatorname{Var} & \left\{\sum_{j=1}^{n} \mu_{j} \tilde{x}_{i j}-\tilde{x}_{i o}\right\}=\operatorname{Var}\left\{\sum_{j=1}^{n} \mu_{j} x_{i j}+\left(\mu_{o}-1\right) x_{i o}\right\} \\
& =\operatorname{Var}\left(\sum_{j=1}^{n} \mu_{j} x_{i j}\right)+\operatorname{Var}\left(\left(\mu_{o}-1\right) x_{i o}\right)+2 \operatorname{Cov}\left(\sum_{j=1}^{n} \mu_{j} x_{i j},\left(\mu_{o}-1\right) x_{i o}\right)
\end{aligned}
$$

Therefore,

$$
\sigma_{i}^{I}(\mu)^{2}=\sum_{j \neq 0} \sum_{k \neq 0} \mu_{i} \mu_{k} \operatorname{Cov}\left(\tilde{x}_{i j}, \tilde{x}_{i k}\right)+2\left(\mu_{o}-1\right) \sum_{j \neq 0} \mu_{j} \operatorname{Cov}\left(\tilde{x}_{i j}, \tilde{x}_{i o}\right)+\left(\mu_{o}-1\right)^{2} \operatorname{Var}\left(\tilde{x}_{i o}\right) \text {, }
$$

and

$$
\begin{aligned}
& \left(\sigma_{i}^{o}(\mu)\right)^{2}=\sum_{j \neq 0} \sum_{k \neq 0} \mu_{i} \mu_{k} \operatorname{Cov}\left(\tilde{x}_{i j}, \tilde{x}_{i k}\right)+2\left(\mu_{o}-1\right) \sum_{j \neq 0} \mu_{j} \operatorname{Cov}\left(\tilde{x}_{i j}, \tilde{x}_{i o}\right) \\
& +\left(\mu_{o}-\eta\right)^{2} \operatorname{Var}\left(\tilde{x}_{i o}\right), \\
& \left(\sigma_{r}^{D}(\eta, \mu)\right)^{2}=\sum_{i \neq 0} \sum_{j \neq 0} \mu_{i} \mu_{j} \operatorname{Cov}\left(\tilde{y}_{r i}, \tilde{y}_{r j}\right)+2\left(\mu_{o}-\eta\right) \sum_{i \neq 0} \mu_{i} \operatorname{Cov}\left(\tilde{y}_{r i}, \tilde{y}_{r o}\right) \\
& +\left(\mu_{o}-1\right)^{2} \operatorname{Var}\left(\tilde{y}_{r o}\right), \\
& \left(\sigma_{r}^{N}(\mu)\right)^{2}=\sum_{j \neq 0} \sum_{k \neq 0} \mu_{i} \mu_{k} \operatorname{Cov}\left(\tilde{y}_{r i}, \tilde{y}_{r j}\right)+2\left(\mu_{o}-1\right) \sum_{j \neq 0} \mu_{j} \operatorname{Cov}\left(\tilde{y}_{r i}, \tilde{y}_{r o}\right) \\
& +\left(\mu_{o}-\eta\right)^{2} \operatorname{Var}\left(\tilde{x}_{i o}\right) .
\end{aligned}
$$

It is obvious, from the forms of $\sigma_{i}^{o}(\lambda), \sigma_{r}^{D}(\lambda)$, and $\sigma_{r}^{N}(\lambda)$ that Model (23) is a nonlinear program. We demonstrate that this non-linear program can be transformed to a quadratic program. Assume that $w_{i}^{I}, w_{r}^{D}$, and $w_{r}^{N}$ are nonnegative variables. Replacing $w_{i}^{I}$, $w_{r}^{D}$, and $w_{r}^{N}$ respectively, by $\sigma_{i}^{I}(\lambda), \sigma_{r}^{D}(\lambda)$, and $\sigma_{r}^{N}(\lambda)$ and adding the following quadratic equality constraints

$$
\left(w_{i}^{I}\right)^{2}=\left(\sigma_{\mathrm{i}}^{\mathrm{I}}(\mu)\right)^{2}, \quad\left(w_{r}^{D}\right)^{2}=\left(\sigma_{r}^{D}(\mu)\right)^{2},\left(w_{r}^{N}\right)^{2}=\left(\sigma_{r}^{N}(\mu)\right)^{2}
$$

Hence, Model (23) is transformed to a quadratic programming problem.

$$
\begin{aligned}
& \left(w_{i}^{I}\right)^{2}=\sum_{j \neq 0} \sum_{k \neq 0} \mu_{i} \mu_{k} \operatorname{Cov}\left(\tilde{x}_{i j}, \tilde{x}_{i k}\right)-2 \sum_{j \neq 0} \mu_{j} \operatorname{Cov}\left(\tilde{x}_{i j}, \tilde{x}_{i o}\right)+\operatorname{Var}\left(\tilde{x}_{i o}\right), \\
& \left(w_{r}^{D}\right)^{2}=\sum_{i \neq 0} \sum_{j \neq 0} \mu_{i} \mu_{j} \operatorname{Cov}\left(\tilde{y}_{r i}, \tilde{y}_{r j}\right)-2 \eta \sum_{i \neq 0} \mu_{i} \operatorname{Cov}\left(\tilde{y}_{r i}, \tilde{y}_{r o}\right)+\operatorname{Var}\left(\tilde{y}_{r o}\right), \\
& \left(w_{r}^{N}\right)^{2}=\sum_{i \neq 0} \sum_{j \neq 0} \mu_{i} \mu_{j} \operatorname{Cov}\left(\tilde{y}_{r i}, \tilde{y}_{r j}\right)-2 \sum_{i \neq 0} \mu_{i} \operatorname{Cov}\left(\tilde{y}_{r i}, \tilde{y}_{r o}\right)+\operatorname{Var}\left(\tilde{y}_{r o}\right) .
\end{aligned}
$$

This problem, which is free of chance elements, is the preferred 'deterministic equivalent' for Model (10) - a term which is justified for the reason that an optimal selection 
of the variables in Model (11) will also be optimal for Model (10) and, vice versa, an optimal solution of Model (10) will also be optimal for Model (11).

Although void of chance elements, Model (11) is a nonlinear programming problembecause of the functional forms of $\delta_{r}^{o}(\eta, \mu)$ and $\sigma_{i}^{I}(\mu)$. Utilizing techniques developed in Cooper et al. (1996), it can be converted into a quadratic programming problem and solved using algorithms available for this class of problems.

We now notice that if the prearranged value of $\alpha$ is equivalent to 0.5 , the stochastic inefficiencies and efficiencies can then be attained from Model (1) if this deterministic nondiscretionary model is based on mean values of inputs and outputs. A significant result in this case is that the stochastic inefficiencies and efficiencies recognized for each $\mathrm{DMU}_{o}$ are similar as those obtained from this deterministic model formed from merely the input and output means.

\section{The relationships between the stochastic and nondiscretionary models}

Now suppose that all the inputs and outputs are statistically independent. Letting $\sigma_{i j}^{I}$ represent the standard deviation of $\tilde{x}_{i j}$ and letting $\sigma_{r j}^{o}$ represent the standard deviation of $\tilde{y}_{r j}$, we have $\sigma_{r}^{o}(\mu)=\left[\sum_{j \neq 0} \mu_{j}^{2}\left(\sigma_{r j}^{o}\right)^{2}+\left(\eta-\mu_{o}\right)^{2}\left(\sigma_{r o}^{o}\right)^{2}\right]^{1 / 2} \leq \sum_{j \neq 0} \mu_{j} \sigma_{r j}^{o}+\left(\eta-\mu_{o}\right) \sigma_{r o}^{o}$

Since for an optimal solution, $\eta^{*} \geq 1$ and $\mu_{o}^{*} \leq 1$, we also have $\eta-\mu_{o} \geq 0$, thus we likewise obtain

$\sigma_{i}^{I}(\mu)=\left[\sum_{j \neq 0} \mu_{j}^{2}\left(\sigma_{i j}^{I}\right)^{2}+\left(1-\mu_{o}\right)^{2}\left(\sigma_{i o}^{I}\right)^{2}\right]^{1 / 2} \leq \sum_{j \neq 0} \mu_{j} \sigma_{i j}^{I}+\left(1-\mu_{o}\right) \sigma_{i o}^{I}$

We also observe that equality holds in Relation (12), if and only if $\sigma_{r j}^{o}=0$ for all $j \neq o$, and equality holds in Relation (13) if and only if $\sigma_{i j}^{o}=0$ for all $j \neq o$.

(i) If $0<\alpha<0.5$, we have $\Phi^{-1}(\alpha)<0$ and hence

$$
\begin{aligned}
& \sum_{j=1}^{n} x_{i j} \mu_{j}-x_{i o}-\Phi^{-1}(\alpha) \sigma_{i}^{o}(\mu) \leq \sum_{j=1}^{n} x_{i j}^{\prime} \mu_{j}-x_{i o}^{\prime}, \quad i=1, \ldots, m ; \\
& \eta y_{r o}-\sum_{j=1}^{n} y_{r j} \mu_{j}-\Phi^{-1}(\alpha) \sigma_{r}^{o}(\eta, \mu) \leq \eta y_{r o}^{\prime}-\sum_{j=1}^{n} y_{r j}^{\prime} \mu_{j}, \quad r \in D ; \\
& \sum_{j=1}^{n} y_{r j} \mu_{j}-y_{r o}-\Phi^{-1}(\alpha) \sigma_{r}^{o}(\mu) \leq \sum_{j=1}^{n} y_{r j}^{\prime} \mu_{j}-y_{r o^{\prime}}^{\prime} \quad r \in \mathrm{N} .
\end{aligned}
$$


(ii) If $1>\alpha>0.5$, we have $\Phi^{-1}(\alpha)>0$ and hence

$\sum_{j=1}^{n} x_{i j} \mu_{j}-x_{i o}-\Phi^{-1}(\alpha) \sigma_{i}^{o}(\mu) \geq \sum_{j=1}^{n} x_{i j}^{\prime} \mu_{j}-x_{i o}^{\prime}, \quad i=1, \ldots, m$;

$\eta y_{r o}-\sum_{j=1}^{n} y_{r j} \mu_{j}-\Phi^{-1}(\alpha) \sigma_{r}^{o}(\eta, \mu) \leq \eta y_{r o}-\sum_{j=1}^{n} y_{r j} \mu_{j}, \quad r \in D ;$

$\sum_{j=1}^{n} y_{r j} \mu_{j}-y_{r o}-\Phi^{-1}(\alpha) \sigma_{r}^{o}(\mu) \geq \sum_{j=1}^{n} y_{r j} \mu_{j}-y_{r o^{\prime}} \quad r \in N$

where

$$
\begin{array}{ll}
x_{i o}^{\prime}=x_{i o}+\sigma_{i o}^{I} \Phi^{-1}(\alpha), & i=1, \ldots, m ; \\
x_{i j}^{\prime}=x_{i j}+\sigma_{i j}^{I} \Phi^{-1}(\alpha), & j \neq 0, i=1, \ldots, m ; \\
y_{r o}^{\prime}=y_{r o}-\sigma_{r o}^{o} \Phi^{-1}(\alpha), & r \in D ; \\
y_{r J}^{\prime}=y_{r j}-\sigma_{r j}^{o} \Phi^{-1}(\alpha), & r \in D ; \\
y_{r o}^{\prime}=y_{r o}-\sigma_{r o}^{o} \Phi^{-1}(\alpha), & r \in N ; \\
y_{r j}^{\prime}=y_{r j}-\sigma_{r j}^{o} \Phi^{-1}(\alpha), & r \in N .
\end{array}
$$

Lastly, the equality will hold for $r$ and $i$ in Relations (14)-(16) if and only if $\sigma_{i j}^{I}=0$ and $\sigma_{r j}^{o}=0$ for $j \neq o$.

Consider the following linear programming problem

$\operatorname{Max} \eta+\varepsilon\left(\sum_{i=1}^{m} t_{i}^{-}+\sum_{r \in D} t_{r}^{+}\right)$

s.t. $\quad \sum_{j=1}^{n} x_{i j}^{\prime} \mu_{j}+t_{i}^{-}=x_{i o}^{\prime}, \quad i=1, \ldots, m$;

$\eta y_{r o}-\sum_{j=1}^{n} y_{r j} \mu_{j}-t_{r}^{+}=$

$$
r \in D
$$

$\sum_{j=1}^{n} y_{r j}^{\prime} \mu_{j}-t_{r}^{+}=y_{r o^{\prime}}$

$r \in N$

$\sum_{j=1}^{n} \mu_{j}=1$

$t_{r}^{+}=0$,

$r \in N$;

$\mu_{j} \geq 0$,

$j=1, \ldots, n$;

$t_{i}^{-} \geq 0$,

$i=1, \ldots, m$; 
$t_{r}^{+} \geq 0$

$$
r=1, \ldots, s \text {. }
$$

This is simply the nondiscretionary model represented in Model (1) for $\mathrm{DMU}_{o}$ with the adjusted input and output values $\left(x_{j}^{\prime}, y_{j}^{\prime}\right)$ as defined in Relations (20)-(25) for $\mathrm{DMU}_{j}$, $j=1, \ldots, n$.

\section{Results}

We now illustrate the following results,

Theorem 1. For $0<\alpha<0.5$

(i) If $\mathrm{DMU}_{o}$ is stochastic efficient, then $\mathrm{DMU}_{o}$ is efficient for the adjusted inputs and outputs in the deterministic Model (26);

(ii) If $\mathrm{DMU}_{o}$ is inefficient for the adjusted inputs and outputs in Model (26), then $\mathrm{DMU}_{o}$ is stochastic inefficient.

Proof $(i)$ Assume to the contrary that $\mathrm{DMU}_{o}$ is inefficient for the adjusted inputs and outputs in Model (26). Then we must have (I) $\eta^{*}>1$ or (II) $\eta^{*}=1$ and $t_{r}^{+}>0$ or $t_{i}^{-}>0$ for at least one $r$ or $i$ in Model (26). Since a solution for Model (26) is also a solution for Model (11), either case will contradict the supposed stochastic efficiency of $\mathrm{DMU}_{o} \square$.

Proof $(i i)$ This follows directly from $(i) \square$.

Theorem 2. For $0.5<\alpha<1$

(i) If $\mathrm{DMU}_{o}$ is efficient for the adjusted inputs and outputs; in Model (26), then $\mathrm{DMU}_{o}$ is stochastic efficient;

(ii) If $\mathrm{DMU}_{o}$ is inefficient for the adjusted inputs and outputs in Model (26), then $\mathrm{DMU}_{o}$ is stochastic inefficient.

Proof. This is analogous to the proof of Theorem $1 \square$.

\section{The relations to sensitivity analysis}

In order to perform sensitivity analysis, we suppose that only $\mathrm{DMU}_{o}$ has random variations in its inputs and outputs,

i.e., $\sigma_{i j}^{I}=0, j \neq o, \sigma_{i o}^{I} \neq 0, \sigma_{r j}^{o}=0,(j \neq o), \sigma_{r o}^{o} \neq 0, \forall i, r$.

In this instance, Model (26) is the same as Model (11), where

$$
\begin{array}{ll}
\dot{x}_{i o}^{\prime}=x_{i o}+\sigma_{i o}^{I} \Phi^{-1}(\alpha), & i=1, \ldots, m ; \\
x_{i j}^{\prime}=x_{i j}, & j \neq 0, \quad i=1, \ldots, m ; \\
y_{r o}^{\prime}=y_{r o}-\sigma_{r o}^{o} \Phi^{-1}(\alpha), & r \in D ; \\
y_{r J}^{\prime}=y_{r J}, & j \neq o, \quad r \in D ;
\end{array}
$$




$$
\begin{array}{ll}
y_{r o}^{\prime}=y_{r o}-\sigma_{r o}^{o} \Phi^{-1}(\alpha), & r \in D ; \\
y_{r J}^{\prime}=y_{r J}, & j \neq 0, \quad r \in N .
\end{array}
$$

Hence, Model (26) is the deterministic equivalent of stochastic Model (10). This sensitivity analysis is completely deterministic. Our chance-constrained approach can be executed by deterministic equivalents that are similar to those utilized in the sensitivity analysis although the conceptual meanings are dissimilar. The matter originally addressed in the chance-constrained formulation diverges and this introduces components, such as the risk interrelated with $\alpha$, that are not present in this sensitivity analysis.

To illustrate the implications of the suppositions, we begin with the following lemma.

\section{Lemma 1.}

(i) For $0<\alpha<0.5$. Suppose that $\left(\bar{\eta}, \bar{\mu}, \bar{t}^{+}, \bar{t}^{-}\right)$is a feasible solution of (26), and is consequently also a feasible solution of Model (10). Consider the transformations

$$
\begin{array}{ll}
\eta=\bar{\eta}, \quad \mu=\bar{\mu} & \\
\mathrm{t}_{\mathrm{i}}^{-}=\overline{\mathrm{t}}_{\mathrm{i}}^{-}-\left(1-\bar{\mu}_{\mathrm{o}}\right) \sigma_{\mathrm{io}}^{\mathrm{I}} \Phi^{-1}(\alpha), & i=1, \ldots, m ; \\
\mathrm{t}_{\mathrm{r}}^{+}=\overline{\mathrm{t}}_{\mathrm{r}}^{+}-\left(\bar{\eta}-\bar{\mu}_{\mathrm{o}}\right) \sigma_{\mathrm{ro}}^{\mathrm{o}} \Phi^{-1}(\alpha), & r \in D ; \\
\mathrm{t}_{\mathrm{r}}^{+}=\overline{\mathrm{t}}_{\mathrm{r}}^{+}-\left(\bar{\eta}-\bar{\mu}_{\mathrm{o}}\right) \sigma_{\mathrm{ro}}^{\mathrm{o}} \Phi^{-1}(\alpha), & r \in N .
\end{array}
$$

Then $\left(\eta, \mu, t^{+}, t^{-}\right)$is a feasible solution of Model (1).

(ii) For $1>\alpha>0.5$. Suppose that $\left(\eta, \mu, t^{+}, t^{-}\right)$is a feasible solution of Model (1). Consider the transformations

$$
\begin{array}{ll}
\bar{\eta}=\eta, \quad \bar{\mu}=\mu ; & \\
\overline{\mathrm{t}}_{\mathrm{i}}^{-}=\mathrm{t}_{\mathrm{i}}^{-}+\left(1-\bar{\mu}_{\mathrm{o}}\right) \sigma_{\mathrm{io}}^{\mathrm{I}} \Phi^{-1}(\alpha), & i=1, \ldots, m ; \\
\overline{\mathrm{t}}_{\mathrm{r}}^{+}=\mathrm{t}_{\mathrm{r}}^{+}+\left(\bar{\eta}-\bar{\mu}_{\mathrm{o}}\right) \sigma_{\mathrm{ro}}^{\mathrm{o}} \Phi^{-1}(\alpha), & r \in D ; \\
\overline{\mathrm{t}}_{\mathrm{r}}^{+}=\mathrm{t}_{\mathrm{r}}^{+}+\left(\bar{\eta}-\bar{\mu}_{\mathrm{o}}\right) \sigma_{\mathrm{ro}}^{\mathrm{o}} \Phi^{-1}(\alpha), & r \in N .
\end{array}
$$

We then have $\left(\bar{\eta}, \bar{\mu}, \bar{t}^{+}, \bar{t}^{-}\right)$as a feasible solution of Model (26), which is the deterministic equivalent of Model (26) under the suppositions made at the start of this section.

Proof. This is straightforward upon substitution into Models (1) and (26), respectively $\square$.

Also, based on what we have previously discussed for Model (11), we have the following immediate results.

Theorem 3. For $\alpha=0.5$. The inefficiency versus the efficiency of $\mathrm{DMU}_{o}$ in the input-output mean Model (1) is similar as in the stochastic Model (10). Note that the input-output vectors in (1) are mean values of random variables. 
Theorem 4. For $0<\alpha<0.5$.

(i) Assuming $\mathrm{DMU}_{o}$ is efficient with $\mathrm{DMU}_{o} \in E \cup E^{\prime}$ in the input-output mean Model (1), then $\mathrm{DMU}_{o} \in \mathrm{E}$ in the stochastic Model (10);

(ii) Assuming $\mathrm{DMU}_{o} \in \mathrm{F}$ in the input-output mean Model (1), then $\mathrm{DMU}_{o} \in \mathrm{E}$ in the stochastic Model (10);

(iii) Assuming $\mathrm{DMU}_{o} \in \mathrm{N}$ in the input-output mean Model (1), then $\mathrm{DMU}_{o} \in \mathrm{N}$ in the stochastic Model (10) if $\frac{\beta_{i}^{-*}}{\left(-\Phi^{-1}(\alpha)\right)}>\sigma_{\text {io }}^{\mathrm{I}}$ and $\frac{\beta_{r}^{+*}}{\left(-\Phi^{-1}(\alpha)\right)}>\sigma_{\text {ro }}^{\mathrm{o}}$, where, for $0.5>\alpha$ we have $\Phi^{-1}(\alpha)<0$. Here $\sum_{i=1}^{m} \beta_{i}^{-*}+\sum_{r=1}^{s} \beta_{r}^{+*}$ is the optimal value of

$\max \sum_{i=1}^{m} \beta_{i}^{-}+\sum_{r \in D} \beta_{r}^{+}$

s.t. $\sum_{i=1}^{m} x_{i j} \mu_{j}+\beta_{i}^{-} \leq x_{i o,} \quad i=1, \ldots, m$;

$\sum_{j=1}^{n} y_{r j} \mu_{j}-\beta_{j}^{+} \geq y_{\text {ro, }} \quad r \in D$;

$\sum_{j=1}^{n} y_{r j} \mu_{j}-\beta_{j}^{+} \geq y_{r o,} \quad r \in N$;

$\beta_{i}^{-} \geq 0, \beta_{r}^{+}, \mu_{j} \geq 0, \quad r=1, \ldots, s ; i=1, \ldots, m$; and $j=1, \ldots, n$.

Proof $(i)$. To prove $(i)$ we note that $y_{r o} \leq y_{r o}^{\prime}$ and $x_{i o} \geq x_{i o}^{\prime}$ from Relations (27), (28) and (29). Therefore, if $\mathrm{DMU}_{o}$ is efficient in Model (1), then $\mathrm{DMU}_{o}$ is also efficient in Model (26). Therefore, $\mathrm{DMU}_{o}$ is stochastic efficient as stated in Definition 3. Consider a feasible solution $\left(\eta, \mu, t^{+}, t^{-}\right)$of Model (26) with $\eta=1, \mu_{o}=1$, and $\mu_{j}=0(j \neq 0), t^{+}=0$, and $t^{-}=0$. It is clearly an optimal solution of Model (26). We now show that this is the unique optimal solution. Assume on the contrary that there is another optimal solution $\left(\bar{\eta}, \bar{\mu}, \bar{t}^{+}, \bar{t}^{-}\right)$of (26) with $\bar{\eta}=1$ and $0 \leq \bar{\mu}_{o}<1$. Consider the transformation $\left(\eta^{*}, \mu^{*}, t^{+*}, t^{-*}\right)$ of $\left(\bar{\eta}, \bar{\mu}, \bar{s}^{+}, \bar{s}^{-}\right)$ in Lemma $1(i)$. This is a feasible solution of Model (1) with $\eta^{*}=\bar{\eta}=1$. However, since $\bar{\mu}_{o}<1$, we have

$t_{r}^{+*}=\bar{t}_{r}^{+}-\left(\bar{\eta}-\bar{\mu}_{o}\right) \sigma_{r o}^{o} \Phi^{-1}(\alpha)$

$=\bar{t}_{r}^{+}-\left(1-\mu_{o}\right) \sigma_{\text {ro }}^{o} \Phi^{-1}(\alpha)>\bar{t}_{r}^{+} \geq 0, \quad r \in D$;

This, nevertheless, contradicts $\mathrm{DMU}_{o} \in \mathrm{EUE}^{\prime}$ in Model (1). Consequently, $\left(\bar{\eta}, \bar{\mu}, \bar{t}^{+}, \bar{t}^{-}\right)$is the unique optimal solution of Model (26) and $\mathrm{DMU}_{o} \in \mathrm{E}$ in the stochastic Model (10) $\square$ 
(ii) To prove (ii) we first demonstrate that $\mathrm{DMU}_{o}$ is efficient in Model (26). Assume on the contrary that $\mathrm{DMU}_{o}$ is inefficient in Model (26). Inefficiency for $\mathrm{DMU}_{o}$ amounts to $\mathrm{DMU}_{o}$ being dominated by the other DMUs. In this case there exists a $\mu \geq 0$ with $\mu_{o}=0$ and $\sum_{j \neq o} \mu_{j}=1$ such that

$\sum_{j \neq 0} x_{i j} \mu_{j}=\sum_{j \neq 0} x_{i j}^{\prime} \mu_{j} \leq x_{i o}^{\prime}=x_{i o}-\sigma_{\mathrm{io}}^{\mathrm{o}} \Phi^{-1}(\alpha)<x_{i o}, \quad i=1, \ldots, m$;

$\sum_{j \neq 0} y_{r j} \mu_{j}=\sum_{j \neq 0} y_{r j}^{\prime} \mu_{j} \geq y_{r o}^{\prime}=y_{r o}-\sigma_{\mathrm{ro}}^{\mathrm{o}} \Phi^{-1}(\alpha)>y_{r o}, \quad r \in D ;$

$\sum_{j \neq 0} y_{r j} \mu_{j}=\sum_{j \neq 0} y_{r j}^{\prime} \mu_{j} \geq y_{r o}^{\prime}=y_{r o}-\sigma_{\mathrm{ro}}^{\mathrm{o}} \Phi^{-1}(\alpha)>y_{r o}, \quad r \in N$.

From the second set of these relations we can see that we need $\eta>1$ to attain the equality that optimality requires for at least some of these $r \in D$ constraints. The remaining constraints are satisfied by an appropriate selection of slacks. Therefore, we have a feasible solution with $\eta>1$ and possibly non-zero slacks. This contradicts the supposition that $\mathrm{DMU}_{o} \in \mathrm{F}$ in Model (1). Thus $\mathrm{DMU}_{o}$ is efficient in Model (26). Consider a feasible solution $\left(\eta, \mu, t^{+}, t^{-}\right)$of Model (26) with $\eta=1, \mu_{o}=1$ and $\mu_{j}=0(j \neq 0)$, and $t^{+}=0$, and $t^{-}=0$. It is obvious that $\left(\eta, \lambda, t^{+}, t^{-}\right)$is an optimal solution of Model (26). We want to demonstrate, nevertheless, that it is a unique optimal solution so that $\mathrm{DMU}_{o} \in \mathrm{E}$. Assume on the contrary that there is another optimal solution $\left(\bar{\eta}, \bar{\mu}, \bar{t}^{+}, \bar{t}^{-}\right)$of Model (26) with $\bar{\eta}=1,0 \leq \bar{\mu}_{o}<1$, $\bar{t}^{+}=0, \bar{t}^{-}=0$. Consider the transformation $\left(\eta^{*}, \mu^{*}, t^{+*}, t^{-*}\right)$ of $\left(\bar{\eta}, \bar{\mu}, \bar{t}^{+}, \bar{t}^{-}\right)$as given in Lemma $1(i)$. This is a feasible solution of Model (1). However, since $\bar{\mu}_{o}<1$, we have

$$
\begin{array}{ll}
\mathrm{t}_{\mathrm{i}}^{+*}=\overline{\mathrm{t}}_{\mathrm{i}}^{+}-\left(\bar{\eta}-\bar{\mu}_{\mathrm{o}}\right) \sigma_{\mathrm{io}}^{\mathrm{I}} \Phi^{-1}(\alpha) & \\
=\overline{\mathrm{t}}_{\mathrm{i}}^{+}-\left(1-\bar{\mu}_{\mathrm{o}}\right) \sigma_{\mathrm{io}}^{\mathrm{I}} \Phi^{-1}(\alpha)>\overline{\mathrm{t}}_{\mathrm{i}}^{+}=0, & \\
\mathrm{t}_{\mathrm{r}}^{+*}=\overline{\mathrm{t}}_{\mathrm{r}}^{+}-\left(\bar{\eta}-\bar{\mu}_{\mathrm{o}}\right) \sigma_{\mathrm{ro}}^{\mathrm{o}} \Phi^{-1}(\alpha) & r \in D ; \\
=\overline{\mathrm{t}}_{\mathrm{r}}^{+}-\left(1-\bar{\mu}_{\mathrm{o}}\right) \sigma_{\mathrm{ro}}^{\mathrm{o}} \Phi^{-1}(\alpha)>\overline{\mathrm{t}}_{\mathrm{r}}^{+} \geq 0, & \\
\mathrm{t}_{\mathrm{r}}^{+*}=\overline{\mathrm{t}}_{\mathrm{r}}^{+}-\left(\bar{\eta}-\bar{\mu}_{\mathrm{o}}\right) \sigma_{\mathrm{ro}}^{\mathrm{o}} \Phi^{-1}(\alpha) & N \in D . \\
=\overline{\mathrm{t}}_{\mathrm{r}}^{+}-\left(1-\bar{\mu}_{\mathrm{o}}\right) \sigma_{\mathrm{ro}}^{\mathrm{o}} \Phi^{-1}(\alpha)>\overline{\mathrm{t}}_{\mathrm{r}}^{+} \geq 0, &
\end{array}
$$

Since

$$
\begin{array}{ll}
x_{i o}=\sum_{j=1}^{n} x_{i j} \mu_{j}^{*}+t_{i}^{+*}>\sum_{j=1}^{n} x_{i j} \mu_{j}^{*}, & i=1, \ldots, m ; \\
y_{r o}=\sum_{j=1}^{n} y_{r j} \mu_{j}^{*}-t_{r}^{+*}<\sum_{j=1}^{n} y_{r j} \mu_{j}^{*}, & r \in D ;
\end{array}
$$


$y_{r o}=\sum_{j=1}^{n} y_{r j} \mu_{j}^{*}-t_{r}^{+*}<\sum_{j=1}^{n} y_{r j} \mu_{j}^{*}$.

$r \in N$

which contradicts the condition prescribed in (ii) that $\mathrm{DMU}_{o} \in \mathrm{F}$ in Model (1). Thus $\mathrm{DMU}_{o} \in$ E in Model (26), i.e., $\mathrm{DMU}_{o} \in \mathrm{E}$ in the stochastic Model (10).

(ii) Finally turning to (iii), assume that $\left(\beta^{+*}, \beta^{-*}, \mu^{*}\right)$ is an optimal solution of Model (30). As a condition for being the maximum, we must have

$\sum_{j=1}^{n} x_{i j} \mu_{j}^{*}=x_{i o}+\beta_{i}^{-*}$, $i=1, \ldots, m$;

$\sum_{j=1}^{n} y_{r j} \mu_{j}^{*}=y_{r o}+\beta_{r}^{+*}$, $r \in D$

$\sum_{j=1}^{n} y_{r j} \mu_{j}^{*}=y_{r o}+\beta_{r}^{+*}$,

$r \in N$.

By the conditions prescribed in (iii) we have $\beta_{i}^{-*} /\left(\Phi^{-1}(\alpha)\right)>\sigma_{\text {io }}^{\mathrm{I}}$ and $\beta_{r}^{+*} /\left(\Phi^{-1}(\alpha)\right)>\sigma_{\text {ro. }}^{\text {o }}$ Therefore we must also have

$$
\begin{aligned}
& x_{i o}^{\prime}=x_{i o}+\sigma_{\mathrm{io}}^{\mathrm{I}} \Phi^{-1}(\alpha)>x_{i o}-\beta_{i}^{-*}=\sum_{j \neq 0}^{n} x_{i j} \mu_{j}^{*}=x_{i o} \mu_{o}^{*} \\
& \geq \sum_{j \neq 0}^{n} x_{i j} \mu_{j}^{*}+\left(x_{i o}-\sigma_{\mathrm{io}}^{\mathrm{I}} \Phi^{-1}(\alpha)\right) \mu_{o}^{*}=\sum_{j=1}^{n} x_{i j}^{\prime}+\mu_{j}^{*}, \quad i=1, \ldots, m ; \\
& y_{r o}^{\prime}=y_{r o}-\sigma_{\mathrm{ro}}^{\mathrm{o}} \Phi^{-1}(\alpha)<y_{r o}+\beta_{r}^{+*}=\sum_{j \neq 0}^{n} y_{r j} \mu_{j}^{*}+y_{r o} \mu_{o}^{*} \\
& \leq \sum_{j \neq 0}^{n} y_{r j} \mu_{j}^{*}+\left(y_{r o}-\sigma_{\mathrm{ro}}^{\mathrm{o}} \Phi^{-1}(\alpha)\right) \mu_{o}^{*}=\sum_{j=1}^{n} y_{i j}^{\prime}+\mu_{j}^{*}, \quad r \in D ; \\
& y_{r o}^{\prime}=y_{r o}-\sigma_{\mathrm{ro}}^{\mathrm{o}} \Phi^{-1}(\alpha)<y_{r o}+\beta_{r}^{+*}=\sum_{j \neq 0}^{n} y_{r j} \mu_{j}^{*}+y_{r o} \mu_{o}^{*} \\
& \leq \sum_{j \neq 0}^{n} y_{r j} \mu_{j}^{*}+\left(y_{r o}-\sigma_{\mathrm{ro}}^{\mathrm{o}} \Phi^{-1}(\alpha)\right) \mu_{o}^{*}=\sum_{j=1}^{n} y_{i j}^{\prime}+\mu_{j}^{*}, \quad r \in N .
\end{aligned}
$$

This means that $x_{i o}^{\prime}$ and $y_{r o}^{\prime}$ are dominated by a convex combination of other DMUs. Thus $\mathrm{DMU}_{o}$ is inefficient in Model (26). Consequently, as claimed, DMU $o \in \mathrm{N}$ in the 
stochastic Model (10) when $\mathrm{DMU}_{o} \in \mathrm{E}$ in the mean Model (1).

Theorem 5. For $0.5<\alpha<1$. (i) Assume $\mathrm{DMU}_{o} \in \mathrm{E}$ in the input-output mean Model (1), then $\mathrm{DMU}_{o} \in \mathrm{E}$ in the stochastic Model (10) if

$\sum_{i=1}^{m} \sigma_{\mathrm{io}}^{\mathrm{I}}+\sum_{r \in D} \sigma_{\mathrm{ro}}^{\mathrm{o}}<\left(\sum_{i=1}^{m} \phi_{\mathrm{i}}^{-*}+\sum_{r \in D} \phi_{\mathrm{r}}^{+*}\right) / \Phi^{-1}(\alpha)$

where $\sum_{i=1}^{m} \phi_{i}^{-*}+\sum_{r \in D} \phi_{r}^{+*}$ is the optimal value of

$\min \sum_{i=1}^{m} \phi_{i}^{-}+\sum_{r \in D} \phi_{r}^{+}$

s.t. $\quad \sum_{j=0}^{n} x_{i j} \mu_{j} \leq x_{i o}-\phi_{i}^{-}$,

$i=1, \ldots, m$;

$\sum_{j \neq 0}^{n} y_{r j} \mu_{j} \geq y_{r o}+\phi_{r}^{+}$

$r \in D$

$\sum_{j \neq 0}^{n} y_{r j} \mu_{j} \geq y_{r o}+\phi_{r}^{+}$

$r \in N$

$\sum_{j \neq 0}^{n} \mu_{j}=1$

$\phi_{i}^{-} \geq 0 ; \phi_{r}^{+} \geq 0 ; \mu_{j} \geq 0(j \neq o)$;

$r=1, \ldots, s ; j=1, \ldots, n ; \quad i=1, \ldots, m$.

(ii) Assuming that $\mathrm{DMU}_{o} \in \mathrm{E}^{\prime} \cup \mathrm{F} \cup \mathrm{N}$ in the input-output mean Model (1), then $\mathrm{DMU}_{o} \in \mathrm{N}$ in the stochastic Model (10).

Proof $(i)$. First we want to demonstrate that $\mathrm{DMU}_{o}$ is stochastic efficient, which is tru it is efficient in Model (26). Assume on the contrary $\mathrm{DMU}_{o}$ is inefficient in Model (26). This implies that there is a $\bar{\mu}$ with $\bar{\mu}_{o}=0, \bar{\mu}_{j} \geq 0(j \neq o)$ and $\sum_{j \neq o} \bar{\mu}_{j}=1$ such that

$$
\begin{array}{lr}
\sum_{j \neq 0}^{n} x_{i j}^{\prime} \bar{\mu}_{j} \leq x_{i o}^{\prime}, & i=1, \ldots, m ; \\
\sum_{\mathrm{j} \neq 0} \mathrm{y}_{\mathrm{rj}}^{\prime} \bar{\mu}_{\mathrm{j}} \geq \mathrm{y}_{\mathrm{ro}}^{\prime}, & \mathrm{r}=1, \ldots, \mathrm{D} ; \\
\sum_{j \neq 0} y_{r j}^{\prime} \bar{\mu}_{j} \geq y_{r o}^{\prime}, & r=1, \ldots, N .
\end{array}
$$

Therefore, by the definitions of $\mathrm{x}^{\prime}$ and $\mathrm{y}^{\prime}$,

$$
\begin{array}{ll}
\sum_{j \neq 0}^{n} x_{i j} \bar{\mu}_{j} \leq x_{i o}-\sigma_{i o}^{\mathrm{I}} \Phi^{-1}(\alpha), & i=1, \ldots, m ; \\
\sum_{j \neq 0} y_{r j} \bar{\mu}_{j} \geq y_{r o}-\sigma_{r o}^{o} \Phi^{-1}(\alpha), & r=1, \ldots, D ; \\
\sum_{j \neq 0} y_{r j} \bar{\mu}_{j} \geq y_{r o}-\sigma_{r o}^{o} \Phi^{-1}(\alpha), & r=1, \ldots, N .
\end{array}
$$


Letting $\bar{\phi}_{i}^{-}=\sigma_{\mathrm{i} o}^{\mathrm{I}} \Phi^{-1}(\alpha), i=1, \ldots, m, \bar{\phi}_{r}^{+}=\sigma_{r o}^{o} \Phi^{-1}(\alpha), r=1, \ldots, D$, and $\bar{\phi}_{r}^{+}=$ $\sigma_{\mathrm{ro}}^{\mathrm{o}} \Phi^{-1}(\alpha), r=1, \ldots, N$. We find that $\left(\bar{\phi}^{+}, \bar{\phi}^{-}, \bar{\mu}\right)$ satisfies Model (32) with $\sum_{i=1}^{m} \bar{\phi}_{i}^{-}+$ $\sum_{r \in D} \bar{\phi}_{r}^{+}<\sum_{i=1}^{m} \phi_{i}^{-*}+\sum_{r \in D} \phi_{r}^{+*}$. This contradicts the assumption that $\sum_{i=1}^{m} \phi_{i}^{-*}+\sum_{r \in D} \phi_{r}^{+*}$ is the optimal value of Model (32). Thus we cannot have $\mathrm{DMU}_{o}$ inefficient. Now, to complete the proof for $(i)$, we want to demonstrate that $\mathrm{DMU}_{o}$ is an extreme point of Model (26). Assume on the contrary it is not an extreme point of Model (26). Then there is a $\hat{\mu}$ with $\hat{\mu}_{o}=0, \hat{\mu}_{j} \geq 0(j \neq o)$ and $\sum_{j \neq o} \hat{\mu}_{j}=1$ such that

$\sum_{j \neq 0} x_{i j} \hat{\mu}_{j}=x_{i o}^{\prime}=x_{i o}+\sigma_{i o}^{o} \Phi^{-1}(\alpha), \quad i=1, \ldots, m$

$\sum_{j \neq 0} y_{r j} \hat{\mu}_{j}=y_{r o}^{\prime}=y_{r o}-\sigma_{r o}^{o} \Phi^{-1}(\alpha), \quad r=1, \ldots, D$

$\sum_{j \neq 0} y_{r j} \hat{\mu}_{j}=y_{r o}^{\prime}=y_{r o}-\sigma_{r o}^{o} \Phi^{-1}(\alpha), \quad r=1, \ldots, N$

See Relations (27)-(29). Let $\hat{\phi}_{i}^{-}=\sigma_{i o}^{I} \Phi^{-1}(\alpha), i=1, \ldots, m, \hat{\phi}_{r}^{+}=\sigma_{r o}^{o} \Phi^{-1}(\alpha), r=$ $1, \ldots, D$, and $\hat{\phi}_{r}^{+}=\sigma_{r o}^{o} \Phi^{-1}(\alpha), r=1, \ldots, N$. We then have $\left(\hat{\phi}^{-}, \hat{\phi}^{+}, \bar{\mu}\right)$ satisfies Model (32) with $\sum_{\mathrm{i}=1}^{\mathrm{m}} \widehat{\phi}^{-}+\sum_{r \in D} \hat{\phi}_{r}^{+}<\sum_{i=1}^{m} \phi_{r}^{-*} \sum_{r \in D} \phi_{r}^{+*}$, a contradiction of the assumption that $\phi_{r}^{-*}$ and $\phi_{r}^{+*}$ are optimal for Model (32).

(ii) Since $\mathrm{DMU}_{o} \in \mathrm{E}^{\prime} \cup F \cup N$ in the input-output mean Model (1), there exists $\bar{\mu}$ with $\bar{\mu}_{o}=0$, $\bar{\mu}_{j} \geq 0(j \neq 0)$ and $\sum_{j \neq o} \bar{\mu}_{j}=1$ such that

$$
\begin{array}{rlrl}
x_{i o} & =\sum_{j \neq 0} x_{i j} \bar{\mu}_{j}=\sum_{j \neq 0} x_{i j}^{\prime} \bar{\mu}_{j}<x_{i o}+\sigma_{i o}^{I} \Phi^{-1}(\alpha)=x_{i o}^{\prime}, & i=1, \ldots, m ; \\
y_{r o}=\sum_{j \neq 0} y_{r j} \bar{\mu}_{j}=\sum_{j \neq 0} y_{r j}^{\prime} \bar{\mu}_{j}<y_{r o}-\sigma_{r o}^{o} \Phi^{-1}(\alpha)=y_{r o}^{\prime}, & r=1, \ldots, D ; \\
y_{r o}=\sum_{j \neq 0} y_{r j} \bar{\mu}_{j}=\sum_{j \neq 0} y_{r j}^{\prime} \bar{\mu}_{j}<y_{r o}-\sigma_{r o}^{o} \Phi^{-1}(\alpha)=y_{r o}^{\prime}, & r=1, \ldots, N .
\end{array}
$$

i.e., $\mathrm{DMU}_{o}$ is strictly dominated by a DMU which is a convex combination of the other DMUs in Model (26). Hence, DMU $\mathrm{D}_{o} \in N$ in the stochastic Model (10) $\square$.

Theorem 6. For $0<\alpha<0.5$.

(i) Assuming that $\mathrm{DMU}_{o} \in \mathrm{E}$ in the stochastic Model (10), then $\mathrm{DMU}_{o} \in \mathrm{E}$ in the inputoutput mean Model (1) if

$$
\sum_{i=1}^{m} \sigma_{\mathrm{io}}^{\mathrm{I}}+\sum_{r \in D} \sigma_{\mathrm{ro}}^{\mathrm{o}}<\left(\sum_{i=1}^{m} \phi_{\mathrm{i}}^{-*}+\sum_{r \in D} \phi_{\mathrm{r}}^{+*}\right) / \Phi^{-1}(\alpha)
$$


where $\sum_{i=1}^{m} \phi_{i}^{-*}+\sum_{r \in D} \phi_{r}^{+*}$ is the optimal value of

$\min \sum_{i=1}^{m} \phi_{i}^{-}+\sum_{r \in D} \phi_{r}^{+}$

s.t.

$\sum_{j \neq 0}^{n} x_{i j} \mu_{j} \leq x_{i o}^{\prime}+\phi_{i}^{-}, \quad i=1, \ldots, m$;

$\sum_{j \neq 0}^{n} y_{r j} \geq y_{r o}^{\prime}-\phi_{r}^{+}, \quad r \in D$

$\sum_{j \neq 0}^{n} y_{r j} \geq y_{r o}^{\prime}-\phi_{r}^{+}, \quad r \in N$

$\sum_{j \neq 0}^{n} \mu_{j}=1$

$\phi_{i}^{-} \geq 0 ; \quad \phi_{r}^{+} \geq 0 ; \mu_{j} \geq 0(j \neq o) ;$

$r=1, \ldots, s ; j=1, \ldots, n ; i=1, \ldots, m$.

(ii) Assuming that $\mathrm{DMU}_{o} \in \mathrm{E}^{\prime} \cup F \cup \mathrm{N}$ in the stochastic Model (10), then $\mathrm{DMU}_{o} \in \mathrm{N}$ in the input-output mean Model (1).

Proof. This is similar to the proof of Theorem 5 when one replaces $\left(x_{j}, y_{j}\right)$ by $\left(x_{j}^{\prime}, y_{j}^{\prime}\right)$, and note that $x_{j}^{\prime} y_{j}^{\prime}=\left(x_{j}, y_{j}\right)$ for $j \neq o \square$.

Theorem 7. For $0.5<\alpha<1$.

(i) Assuming that $\mathrm{DMU}_{o} \in E \cup E^{\prime}$ in the stochastic Model (10), then $\mathrm{DMU}_{o} \cup \mathrm{E}$ in the inputoutput mean Model (1);

(ii) Assuming that $\mathrm{DMU}_{o} \in \mathrm{F}$ in the stochastic Model (10), then $\mathrm{DMU}_{o} \in \mathrm{E}$ in the input-output mean Model (1).

(iii) Assume $\mathrm{DMU}_{o} \in \mathrm{N}$ in the stochastic Model (10), then $\mathrm{DMU}_{o} \in \mathrm{N}$ in the input-output mean Model (1) if $\beta_{i}^{-*} / \Phi^{-1}(\alpha)>\sigma_{i o}^{I}$ and $\beta_{i}^{+*} / \Phi^{-1}(\alpha)>\sigma_{r o}^{o}$, where $\sum_{i=1}^{m} \beta_{i}^{-*}+\sum_{r \in D} \beta_{r}^{+*}$ is the optimal value of the following model,

$\operatorname{Max} \sum_{i=1}^{n} \beta_{i}^{-}+\sum_{r \in D} \beta_{r}^{+}$

s.t. $\sum_{j=1}^{n} x_{i o}^{\prime} \mu_{\mathrm{j}}-\beta_{i}^{-} \leq x_{i o}^{\prime}, \quad i=1, \ldots, m$; 


$$
\begin{aligned}
& \sum_{j=1}^{n} y_{r j}^{\prime} \mu_{\mathrm{j}}-\beta_{r}^{+} \geq y_{r o}^{\prime}, \quad r \in D ; \\
& \sum_{j=1}^{n} y_{r j}^{\prime} \mu_{\mathrm{j}}-\beta_{r}^{+} \geq y_{r o}^{\prime}, \quad r \in N ; \\
& \beta_{r}^{+} \geq 0 ; \quad \beta_{r}^{-} \geq 0 ; \quad \mu_{\mathrm{j}} \geq 0 ; \\
& r=1, \ldots s ; i=1, \ldots, m ; j=1, \ldots, n .
\end{aligned}
$$

This is similar to the proof of Theorem 4 when one replaces $\left(x_{j}, y_{j}\right)$ by $\left(x_{j}^{\prime}, y_{j}^{\prime}\right) \square$.

Next we present a case study to demonstrate the applicability of the proposed framework and to exhibit the efficacy of the procedures and algorithms.

\section{Case study}

We used the model presented in this study for supplier selection at Infotecx ${ }^{1}$. Infotex was founded in 1988 as a small start-up information technology company with the vision of becoming the industry leader in health informatics. The company is currently one of the largest private software companies in the U.S. providing information technology solutions in the health care industry. Currently, the company has eight subsidiaries each specialized in different healthcare market segments and 27 satellite companies providing sales, installation, and after-sales services. The company taps into its 900 professional staff to reach over 5000 customers. There are 20 main specialized application developers at Infotecx that supply a variety of health informatics solutions, either starting the development of healthcare information system from the ground up, or taking legacy systems and convert them to fulfill new requirements. The data set used in this case study includes specifications on 20 suppliers located in 20 different cities across the U.S. The performance measures utilized in this study are the number of personnel, average time for serving customers, profit margin, and supplier variety. The number of personnel and average time for serving the customers were used as the input variables in the DEA model. Profit margin and supplier variety were considered as the output variables in the DEA model. Moreover, as suggested by Farzipoor Saen (2009), supplier variety is considered as a nondiscretionary output, i.e., this factor is exogenously fixed and cannot be increased by suppliers (at least in the short term). Note that the inputs and outputs selected in this paper are not exhaustive by any means. The actual case study included several additional input and output data which are omitted in this paper for simplicity. Table 2 presents the supplier attributes used in this paper.

\footnotetext{
${ }^{1}$ The name of the company is changed to protect its anonymity.
} 


\section{Insert Table 2 Here}

The computational results from using Model (25) with $\alpha=0.05$ are shown in Table 3. The efficient suppliers are Columbus, Houston, Memphis, and San Francisco. These suppliers are efficient because the following two conditions are both satisfied:

(i) $\eta^{*}=1$, and

(ii) $t_{i}^{-*}=t_{r}^{+}=0, \quad \forall . i, r$.

\section{Insert Table 3 Here}

The visual computational result for this data set is presented in Figure 1. This figure has two coordinates (DMUs and stochastic efficiency) and shows the efficiency of the 20 DMUs under consideration. As shown in these figures, except for the efficient DMUs, the efficiency scores of all the remaining DMUs are greater than one. The efficiency scores for the efficient DMUs are one and their associated slacks are zero.

Insert Figure 1 Here

This example shows the applicability of the proposed novel supplier selection model using chance-constrained DEA with Nondiscretionary Factors and Stochastic Data.

\section{Conclusions and future research directions}

Over the past few decades, increased rivalry caused by globalization and rapid technological advances has motivated organizations to improve their SCM efficiency. Nevertheless, many companies have failed to devote adequate resources for managing their SCM activities. Effective SCM requires effective purchasing strategies and effective purchasing is dependent on optimal supplier selection decisions. In today's competitive operating environment, it is very difficult to produce low cost, high quality products without having satisfactory suppliers.

Purchasing materials have long been recognized as a multi-criteria problem. A concurrent consideration of multiple criteria complicates the supplier selection decisions, even for experienced managers. Competing suppliers have different levels of success under multiple criteria. For example, the supplier with the lowest cost in a given market may not have the best delivery performance or product quality. Although multiple criteria supplier selection problems have been addressed in the literature, the emergence of a nondiscretionary and stochastic situation has been an obstacle for procurement managers searching for the best suppliers. The contributions of this paper are fourfold: (1) We proposed a chance-constrained DEA model for supplier selection; (2) we considered multiple and conflicting criteria in supplier selection decisions; (3) we incorporated nondiscretionary factors and stochastic data in DEA; and (4) we presented a case study and demonstrated the applicability of the method 
to supplier selection decisions.

In this paper a new approach was proposed to assist the decision makers to determine the most efficient suppliers in the presence of both nondiscretionary factors and stochastic data. The problem considered in this study is at the initial stage of investigation and further research can be done based on results of this paper. Some of them are as follows: (1) similar research can be repeated for supplier selection in the presence of both stochastic data and fuzzy data; (2) similar research can be conducted for supplier selection in the presence of both undesirable factors and stochastic data; (3) similar research can be performed for supplier selection in the presence of both stochastic data and slightly non-homogeneous DMUs; and (4) this study applied the proposed model to a supplier selection problem. The proposed model is generic and can be applied to additional problem domains such as market segmentation decisions, personnel selection decisions and location planning decisions. 


\section{References}

Amid, A., Ghodsypour, S.H. \& O'Brien, C. (in press). A weighted max-min model for fuzzy multi-objective supplier selection in a supply chain, International Journal of Production Economics.

Azadeh, A., Ghaderi, S.F., Mirjalili, M., \& Moghaddam, M. (2010a). A DEA approach for ranking and optimisation of technical and management efficiency of a large bank based on financial indicators. International Journal of Operational Research, 9(2), 160-187.

Azadeh, A., Javanmardi, L., \& Saberi, M. (2010b). The impact of decision-making units features on efficiency by integration of data envelopment analysis, artificial neural network, fuzzy C-means and analysis of variance. International Journal of Operational Research, 7(3), $387-411$.

Banker, R.D., \& Morey, R.C. (1986). Efficiency analysis for exogenously fixed inputs and outputs, Operations Research, 34(4), 513-521.

Barbarosoglu, G. \& Yazgac, T. (1997). An application of the analytic hierarchy process to the supplier selection problem. Production and Inventory Management Journal, 38(1), 14-21.

Barla, S.B. (2003). A case study of supplier selection for lean supply by using a mathematical model. Logistics Information Management, 16(6), 451-459.

Bayazit, O. (2006). Use of analytic network process in vendor selection decisions. Benchmarking: An International Journal, 13(5), 566-579.

Cakravastia, A., \& Takahashi, K. (2004). Integrated model for supplier selection and negotiation in a make-to-order environment. International Journal of Production Research, $42(21), 4457-4474$.

Çebi, F., \& Bayraktar, D. (2003). An integrated approach for supplier selection. Logistics Information Management, 16(6), 395-400. 
Chan, F.T.S. (2003). Interactive selection model for supplier selection process: An analytical hierarchy process approach. International Journal Production Research, 41(15), 3549-3579.

Chan, F.T.S., \& Chan, H.K. (2004). Development of the supplier selection model - A case study in the advanced technology industry. Journal of Engineering Manufacture - Part B, 218(12), 1807-1824.

Chan, F.T.S., Chan, H.K., Ip, R.W.L., \& Lau, H.C.W. (2007). A decision support system for supplier selection in the airline industry. Journal of Engineering Manufacture - Part B, 221(4), 741-758.

Charnes, A., \& Cooper, W.W. (1961). Management models and industrial applications of linear programming, I and II. Wiley: New York.

Charnes, A., \& Cooper, W.W. (1963). Deterministic Equivalents for Optimizing and Satisficing under Chance Constraints. Operations Research, 11(1), 18-39.

Charnes A., Cooper, W.W., \& Symonds, G.H. (1958). Cost horizons and certainty equivalents: An approach to stochastic programming of heating oil. Management Science, $4(3), 235-263$.

Charnes, A., Cooper, W.W., \& Rhodes, E. (1978). Measuring the efficiency of decision making units. European Journal of Operational Research, 2(6), 429-444.

Charnes, A., Cooper, W.W., \& Thrall, R.M. (1991). A structure for classifying efficiencies and inefficiencies in data envelopment analysis. Journal of Productivity Analysis, 2(3), 197237.

Chen, C.T., Lin, C.T. \& Huang, S.F. (2006). A fuzzy approach for supplier evaluation and selection in supply chain management. International Journal of Production Economics, 102(2), 289-301. 
Cheng, H., Lu, Y.C., \& Chung, J.T. (2010). Assurance region context-dependent DEA with an application to Taiwanese hotel industry. International Journal of Operational Research, $8(3), 292-312$.

Chou, S.Y., \& Chang, Y.H. (2008). A decision support system for supplier selection based on a strategy-aligned fuzzy SMART approach. Expert System with Applications, 34(4), 22412253.

Choy, K.L., \& Lee, W.B. (2002). A generic tool for the selection and management of supplier relationships in an outsourced manufacturing environment: The application of case based reasoning. Logistics Information Management, 15(4), 235-253.

Choy, K.L., Lee, W.B., \& Lo, V. (2002). Development of a case based intelligent customerSupplier relationship management system. Expert Systems with Applications, 23(3), 281-297.

Choy, K.L., Lee, W.B., \& Lo, V. (2004). An enterprise collaborative management system - A case study of supplier relationship management. The Journal of Enterprise Information Management, 17(3), 191-207.

Choy, K.L., Lee, W.B., \& Lo, V. (2005). A knowledge-based supplier intelligence retrieval system for outsource manufacturing. Knowledge-Based Systems, 18(1), 1-17.

Choy, K.L., Fan, K.K.H., \& Lo, V. (2003a). Development of an intelligent customer-supplier relationship management system: The application of case-based reasoning. Industrial Management and Data Systems, 103(4), 263-274.

Choy, K.L., Lee, W.B., \& Lo, V. (2003b). Design of a case based intelligent supplier relationship management system - The integration of supplier rating system and product coding system. Expert Systems with Applications, 25(1), 87-100.

Cooper, W.W., Deng, H., Huang, Z., \& Li, S.X. (2004) Chance Constrained Programming Approaches to Congestion in Stochastic Data Envelopment Analysis. European Journal of Operational Research, 155(2), 487-501. 
Cooper, W.W., Huang, Z., \& Li., S. (1996). Satisficing DEA models under chance constraints. Annals of Operations Research, 66(4), 279-295.

Cooper, W.W., Ruefli, T.W., Deng, H., Wu, J., \& Zhang, Z. (2008). Are state-owned banks less efficient? A long- vs. short-run Data Envelopment Analysis of Chinese banks. International Journal of Operational Research, 3(5), 533-556.

Ebrahim, R.M., Razmi, J., \& Haleh, H. (2009). Scatter search algorithm for supplier selection and order lot sizing under multiple price discount environment, Advances in Engineering Software, 40(9), 766-776.

Dharmapala, P.S. (2009). Adding value in healthcare service by improving operational efficiency using Data Envelopment Analysis. International Journal of Operational Research, 5(1), 73-88.

Ding, H., Benyoucef, L., \& Xie, X. (2005). A simulation optimization methodology for supplier selection problem. International Journal Computer Integrated Manufacturing, 18(23), 210-224.

Emrouznejad, A., \& Thanassoulis, E. 2010. Measurement of productivity index with dynamic DEA. International Journal of Operational Research, 8(2), 247-260.

Farrell, M.J. (1957). The measurement of productive efficiency. Journal of the Royal Statistical Society A, 120(3), 253-281.

Farzipoor Saen, R. (2005). Developing a nondiscretionary model of slacks-based measure in data envelopment analysis. Applied Mathematics and Computation, 169(2), 1440-1447.

Farzipoor Saen, R. (2006). A decision model for selecting technology suppliers in the presence of nondiscretionary factors. Applied Mathematics and Computation, 181(2), 16091615.

Farzipoor Saen, R. (2007a). Suppliers selection in the presence of both cardinal and ordinal data. European Journal of Operational Research, 183(2), 741-747. 
Farzipoor Saen, R. (2007b). A new mathematical approach for supplier selection: Accounting for non-homogeneity is important. Applied Mathematics and Computation, 185(1), 84-95.

Farzipoor Saen, R. (2009). Using data envelopment analysis for ranking suppliers in the presence of nondiscretionary factors. International Journal of Procurement Management, 2(3), 229-243.

Gencer, C., \& Gürpinar, D. (2007). Analytic network process in supplier selection: A case study in an electronic firm. Applied Mathematical Modeling, 31(11), 2475-2486.

Haq, A.N., \& Kannan, G. (2006). Fuzzy analytical hierarchy process for evaluating and selecting a vendor in a supply chain model. International Journal of Advanced Manufacturing Technology, 29(7-8), 826-835.

Ho, C.T.B. (2007). Performance measurement using data envelopment analysis and financial statement analysis. International Journal of Operational Research, 2(1), 26-38.

Hong, G.H., Park, S.C., Jang, D.S. \& Rho, H.M. (2005). An effective supplier selection method for constructing a competitive supply-relationship. Expert Systems with Applications, 28(4), 629-639.

Hou, J., \& Su, D. (2007). EJB-MVC oriented supplier selection system for mass customization. Journal of Manufacturing Technology Management, 18(1), 54-71.

Huang, S.H., \& Keska, H. (2007). Comprehensive and configurable metrics for supplier selection. International Journal of Production Economics, 105(2), 510-523.

Huang, Z., \& Li, S.X. (2001). Stochastic DEA models with different types of input-output disturbances. Journal of Productivity Analysis, 15(2), 95-113.

Jain, V., Tiwari, M.K., \& Chan F.T.S. (2004). Evaluation of the supplier performance using an evolutionary fuzzy-based approach. Journal of Manufacturing Technology Management, 15(8), 735-744. 
Kahraman, C., Cebeci, U. \& Ulukan, Z. (2003). Multi-criteria supplier selection using fuzzy AHP. Logistics Information Management, 16(6), 382-394.

Karpak, B., Kumcu, E., \& Kasuganti, R.R. (2001). Purchasing materials in the supply chain: Managing a multi-objective task. European Journal of Purchasing and Supply Management, $7(3), 209-216$.

Kwong, C.K., Ip, W.H., \& Chan, J.W.K. (2002). Combining scoring method and fuzzy expert systems approach to supplier assessment: A case study. Integrated Manufacturing Systems, 13(7), 512-519.

Lamberson, L.R., Diederich, D., \& Wuori J. (1976). Quantitative vendor evaluation. Journal of Purchasing and Materials Management, Spring, 19-28.

Land, K.C., Lovell, C.A.K., \& Thore, S. (1993). Chance-constrained data envelopment analysis, Managerial and Decision Economics, 14(6), 541-554.

Li, S.X. (1998). Stochastic and models and variables returns to scales in data envelopment analysis. European Journal of Operational Research, 104(3), 532-548.

Liu, F.H.F. \& Hai, H.L. (2005). The voting analytic hierarchy process method for selecting supplier. International Journal of Production Economic, 97(3), 308-317.

Lopez, F.R. (2007). Strategic supplier selection in the added-value perspective: A CI approach. Information Sciences, 177(5), 1169-1179.

Morita, H., \& Seiford, L.M. (1999). Characteristics on stochastic DEA efficiency- reliability and probability being efficient. Journal of the Operations Research Society of Japan, 42(4), $389-404$.

Mulwa, R., Emrouznejad, A., \& Muhammad, L. (2009). Economic Efficiency of smallholder maize producers in Western Kenya: a DEA meta-frontier analysis. International Journal of Operational Research, 4(3), 250-267. 
Muralidharan, C., Anantharaman, N. \& Deshmukh, S.G. (2002). A multi-criteria group decision-making model for supplier rating. Journal of Supply Chain Management, 38(4), 2233.

Narasimhan, R., Talluri, S. \& Mahapatra, S.K. (2006). Multiproduct, multicriteria model for supplier selection with product life-cycle considerations. Decision Sciences, 37(4), 577-603.

Ng, W.L. (2008). An efficient and simple model for multiple criteria supplier selection problem. European Journal of Operational Research, 186(3), 1059-1067.

Olesen, O.B., \& Petersen N.C. (1995). Chance constrained efficiency evaluation, Management Science, 41(3), 442-457.

Olesen, O.B. (2006) Comparing and Combining Two Approaches for CCDEA, Journal of Productivity Analysis, 26(2), 103-119.

Parkan, C. (2006). An alternative derivation of the basic DEA models for gauging the productive performances of operating entities. International Journal of Productivity and Quality Management, 1(3), 253-271.

Ramanathan, R. (2007). Supplier selection problem: Integrating DEA with the approaches of total cost of ownership and AHP. Supply Chain Management: An International Journal, 12(4), 258-261.

Ray, S.C. (1988). Data Envelopment analysis, nondiscretionary inputs and efficiency: An alternative interpretation, Socio-Economic Planning Sciences, 22(4), 167-176.

Sanayei, A., Mousavi, S.F. \& Yazdankhah, A. (2010). Group decision making process for supplier selection with VIKOR under fuzzy environment. Expert Systems with Applications, $37(1), 24-30$. 
Sarkar, A., \& Mohapatra, P.K.J. (2006). Evaluation of supplier capability and performance: A method for supply base reduction. Journal of Purchasing and Supply Management, 12(3), $148-163$.

Sarkis, J., \& Talluri, S. (2002). A model for strategic supplier selection. Journal of Supply Chain, 38(1), 18-28.

Sengupta, J.K. (1982). Efficiency measurement in stochastic input-output systems. International Journal of Systems Science, 13(3), 273-187.

Sengupta, J.K. (1987). Data envelopment analysis for efficiency measurement in the stochastic case. Computers \& Operations Research, 14(1), 117-129.

Sengupta, J.K. (1990). Transformations in stochastic DEA models. Journal of Econometrics, 46(1-2), 109-123.

Sengupta, J.K. (1997). Stochastic efficiency measurement: A new approach. Applied Economics Letters, 4(2), 125-128.

Sengupta, J.K. (1998). Stochastic data envelopment analysis: a new approach. Applied Economics Letters, 5(5), 287-290.

Sengupta, J.K. (2000). Efficiency analysis by stochastic data envelopment analysis. Applied Economics Letters, 7(6), 379-383.

Sevkli, M., Koh, S.C.L., Zaim, S., Demirbag, M., \& Tatoglu E. (2007). An application of data envelopment analytic hierarchy process for supplier selection: A case study of BEKO in Turkey. International Journal of Production Research, 45(9), 1973-2003.

Shin, H., Collier, D.A., \& Wilson, D.D. (2000). Supply management orientation and supplier/buyer performance. Journal of Operations Management, 18(3), 317-333.

Sueyoshi, T. (2000). Stochastic DEA for restructure strategy: An application to a Japanese petroleum company, Omega, 28(4), 385-398. 
Talluri, S. (2002). A buyer-seller game model for selection and negotiation of purchasing bids. European Journal of Operational Research, 143(1), 171-180.

Talluri, S., \& Narasimhan, R. (2003). Vendor evaluation with performance variability: A max-min approach. European Journal of Operational Research, 146(3), 543-552.

Talluri, S., \& Narasimhan, R. (2005). A note on a methodology for supply base optimization. IEEE Transactions on Engineering Management, 52(1), 130-139.

Talluri, S., Narasimhan, R., \& Nair A. (2006). Vendor performance with supply risk: A chance-constrained DEA approach. International Journal of Production Economics, 100(2), 212-222.

Timmerman, E. (1986). An approach to vendor performance evaluation. Journal of Purchasing and Materials Management, 22(4), 2-8.

Tan, K.C. (2001). A framework of supply chain management literature. European Journal of Purchasing and Supply Management, 7(2-3), 39-48.

Verma, R., \& Pullman, M.E. (1998). An analysis of the supplier selection process. Omega, 26(6), 739-750.

Wadhwa, V. \& Ravindran, A.R. (2007). Vendor selection in outsourcing. Computers and Operations Research, 34(12), 3725-3737.

Wang, G., Huang, S.H., \& Dismukes, J.P. (2004). Product-driven supply chain selection using integrated multi-criteria decision-making methodology. International Journal of Production Economics, 91(1), 1-15.

Wong, W.P., Jaruphongsa, W., \& Lee, L.H. (2008). Supply chain performance measurement system: a Monte Carlo DEA-based approach. International Journal of Industrial and Systems Engineering, 3(2), 162-188. 
Xia, W., \& Wu, Z. (2007). Supplier selection with multiple criteria in volume discount environments. Omega, 35(5), 494-504.

Zhang, D., Zhang, J., Lai, K.K., \& Lu Y. (2009). A novel approach to supplier selection based on vague sets group decision, Expert Systems with Applications, 36(5), 9557-9563. 


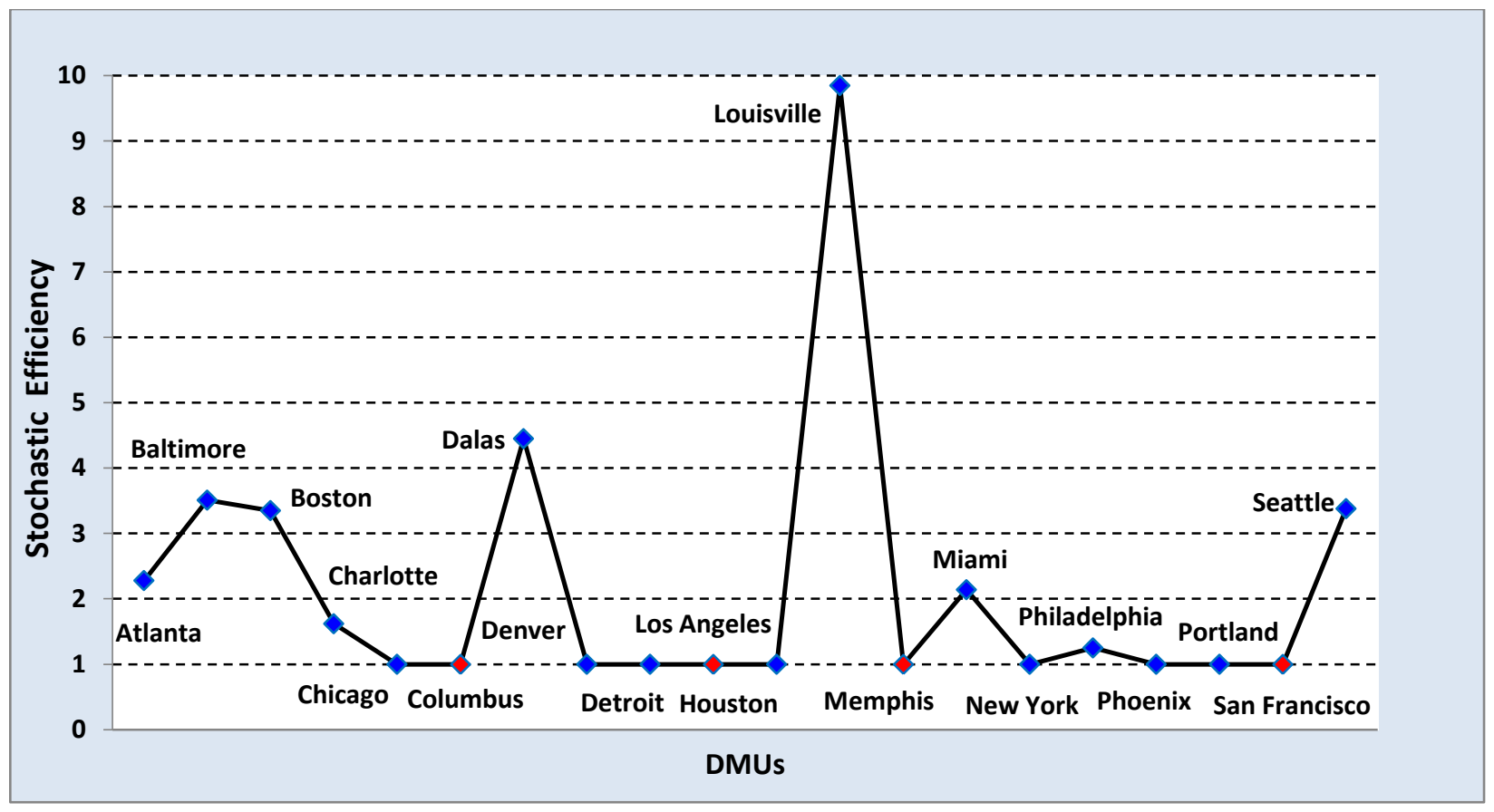

Figure 1. Visual computation results 
Table 1. A summary of the supplier selection methods

\begin{tabular}{|c|c|}
\hline Method & References \\
\hline Analytic hierarchy process (AHP) & $\begin{array}{l}\text { Barbarosoglu and Yazgac (1997), Muralidharan et } \\
\text { al. (2002), Kahraman et al. (2003), Chan (2003), } \\
\text { Çebi and Bayraktar (2003), Chan and Chan (2004), } \\
\text { Wang et al. (2004), Liu and Hai (2005), Chan et al. } \\
\text { (2007), Xia and Wu (2007), Hou and Su (2007), and } \\
\text { Ng (2008) }\end{array}$ \\
\hline Fuzzy set theory & $\begin{array}{l}\text { Jain et al. (2004), Chen et al. (2006), Sarkar and } \\
\text { Mohapatra (2006), Lopez (2007), Amid et al. (in } \\
\text { press), and Sanayei et al. (2010) }\end{array}$ \\
\hline Analytic network process (ANP) & $\begin{array}{l}\text { Sarkis and Talluri (2002), Bayazit (2006), and } \\
\text { Gencer and Gürpinar (2007) }\end{array}$ \\
\hline Mathematical programming & $\begin{array}{l}\text { Talluri and Narasimhan (2003), Talluri and } \\
\text { Narasimhan (2005), Talluri (2002), Hong et al. } \\
\text { (2005), Karpak et al. (2001), Narasimhan et al. } \\
\text { (2006), and Wadhwa and Ravindran (2007) }\end{array}$ \\
\hline Case-based reasoning (CBR) & $\begin{array}{l}\text { Choy et al. (2002), Choy and Lee (2002), Choy et al. } \\
\text { (2003a), Choy et al. (2003b), Choy et al. (2004), and } \\
\text { Choy et al. (2005). }\end{array}$ \\
\hline Data envelopment analysis (DEA) & $\begin{array}{l}\text { Ramanathan (2007), Farzipoor Saen (2006), } \\
\text { Farzipoor Saen (2007a), Farzipoor Saen (2007b), } \\
\text { and Sevkli et al. (2007) }\end{array}$ \\
\hline Simple multi-attribute rating technique & Barla (2003) and Huang and Keska (2007) \\
\hline Scoring method and fuzzy expert system & Kwong et al. (2002) \\
\hline Discrete choice analysis experiments & Verma and Pullman (1998) \\
\hline Genetic algorithm & Ding et al. (2005) \\
\hline Weighted linear models & Lamberson et al. (1976) and Timmerman (1986) \\
\hline Vague sets & Zhang et al. (2009) \\
\hline Scatter search & Ebrahim et al. (2009) \\
\hline
\end{tabular}


Table 2. Related attributes

\begin{tabular}{|c|c|c|c|c|c|c|c|c|}
\hline \multirow{2}{*}{$\begin{array}{c}\text { Supplier } \\
\text { (DMU) }\end{array}$} & \multicolumn{9}{|c|}{$\begin{array}{c}\text { Inputs } \\
\text { personnel }\end{array}$} & $\begin{array}{c}\text { Average time for } \\
\text { serving customers } \\
\text { (hours) }\end{array}$ & \multicolumn{2}{c|}{$\begin{array}{c}\text { Profit margin } \\
\text { (\$1,000) }\end{array}$} & \multicolumn{2}{c|}{ Supplier variety } \\
\cline { 2 - 10 } & Mean & Variance & Mean & Variance & Mean & Variance & Mean & Variance \\
\hline Atlanta & 6 & 0.5 & 70 & 7 & 25 & 3 & 10 & 2 \\
\hline Baltimore & 5 & 1 & 130 & 8 & 17 & 2 & 12 & 3 \\
\hline Boston & 11 & 2 & 125 & 5 & 15 & 1 & 50 & 4 \\
\hline Charlotte & 8 & 1 & 100 & 4 & 25 & 2 & 55 & 5 \\
\hline Chicago & 9 & 1 & 90 & 1 & 30 & 3 & 70 & 7 \\
\hline Columbus & 6 & 2 & 75 & 5 & 50 & 5 & 15 & 5 \\
\hline Dallas & 18 & 1 & 150 & 10 & 14 & 1 & 35 & 5 \\
\hline Denver & 25 & 1 & 280 & 20 & 65 & 0.5 & 42 & 2 \\
\hline Detroit & 12 & 1 & 160 & 10 & 50 & 3 & 60 & 4 \\
\hline Houston & 10 & 1 & 135 & 9 & 40 & 2 & 70 & 9 \\
\hline Los Angeles & 12 & 1 & 120 & 4 & 10 & 4 & 75 & 10 \\
\hline Louisville & 10 & 2 & 95 & 2 & 5 & 1 & 45 & 2 \\
\hline Memphis & 7 & 1 & 70 & 2 & 12 & 2 & 43 & 10 \\
\hline Miami & 11 & 2 & 140 & 5 & 30 & 1 & 5 & 4 \\
\hline New York & 20 & 3 & 140 & 20 & 80 & 2 & 5 & 2 \\
\hline Philadelphia & 23 & 2 & 150 & 25 & 65 & 4 & 8 & 2 \\
\hline Phoenix & 25 & 3 & 120 & 15 & 78 & 3 & 7 & 2 \\
\hline Portland & 10 & 1 & 70 & 1 & 40 & 2 & 25 & 1 \\
\hline San Francisco & 12 & 1 & 115 & 5 & 5 & 1 & 65 & 4 \\
\hline Seattle & 5 & 2 & 80 & 5 & 17 & 1 & 10 & 3 \\
\hline & & & & & & & & \\
\hline
\end{tabular}


Table 3. Overall results

\begin{tabular}{|c|c|c|c|c|c|}
\hline $\begin{array}{c}\text { Supplier } \\
\text { (DMU) }\end{array}$ & $\boldsymbol{t}_{\mathbf{1}}^{-}$ & $\boldsymbol{t}_{\mathbf{2}}^{-}$ & $\boldsymbol{t}_{\mathbf{1}}^{+}$ & $\boldsymbol{t}_{\mathbf{2}}^{+}$ & $\begin{array}{c}\boldsymbol{\eta} \\
(\alpha=0.05)\end{array}$ \\
\hline Atlanta & 2.35 & 0 & 0 & 0 & 2.28 \\
\hline Baltimore & 0 & 43.8 & 0 & 0 & 3.51 \\
\hline Boston & 0 & 1.78 & 0.7 & 0 & 3.35 \\
\hline Charlotte & 0 & 0 & 0 & 0 & 1.62 \\
\hline Chicago & 0.64 & 0 & 0 & 0 & 1 \\
\hline Columbus* & 0 & 0 & 0 & 0 & 1 \\
\hline Dallas & 6.95 & 0 & 0 & 0 & 4.45 \\
\hline Denver & 0.20 & 0.19 & 0 & 0 & 1 \\
\hline Detroit & 0.65 & 0.54 & 2.5 & 0 & 1 \\
\hline Houston* & 0 & 0 & 0 & 0 & 1 \\
\hline Los Angeles & 0.78 & 0.85 & 0 & 0 & 1 \\
\hline Louisville & 3.06 & 0 & 0 & 0 & 9.85 \\
\hline Memphis* & 0 & 0 & 0 & 0 & 1 \\
\hline Miami & 0 & 8.12 & 1.3 & 0 & 2.14 \\
\hline New York & 0.96 & 0.50 & 0.26 & 0 & 1 \\
\hline Philadelphia & 5.8 & 0 & 4.1 & 0 & 1.25 \\
\hline Phoenix & 0.25 & 0 & 0 & 0 & 1 \\
\hline Portland & 0.16 & 0 & 0.7 & 0 & 1 \\
\hline San Francisco* & 0 & 0 & 0 & 0 & 1 \\
\hline Seattle & 0 & 0 & 0 & 0 & 3.38 \\
\hline
\end{tabular}

*Efficient DUMs 